\title{
COMSOL Multiphysics Validation as Simulation Software for Heat Transfer Calculation in Buildings
}

\author{
Building Simulation Software Validation \\ Vladimír Gerlicha*, Kateřina Sulovskáa, Martin Zálešák ${ }^{a}$ \\ ${ }^{a}$ Tomas Bata University in Zlín, Faculty of Applied Informatics, nám. T. G. Masaryka 5555, Zlín, 760 01, \\ the Czech Republic \\ "gerlich@fai.utb.cz, tel.: +420 576033012
}

\begin{abstract}
The main purpose of this article is a presentation of software validation for a calculation of heat transfer in buildings. The heat transfer calculation in the COMSOL Multiphysics is validated by using the analytical models, by the comparative verification provided by the International Energy Agency in the Task 34, and by the comparison with measured data in real building segment. The last model represents transient heat transfer process in an environment with complicated bindings. The similarity between the COMSOL Multiphysics results and other software tools for building simulations was investigated using the Task 34 results with minor dissimilarities. The comparison of simulation results with measured data is described in the paper with sufficient accuracy. The main deviation between the simulation and measured temperature data was caused by the precise calculation of the convective heat transfer coefficient value.
\end{abstract}

Keywords: heat transfer; building simulation; benchmark; software validation; COMSOL Multiphysics 


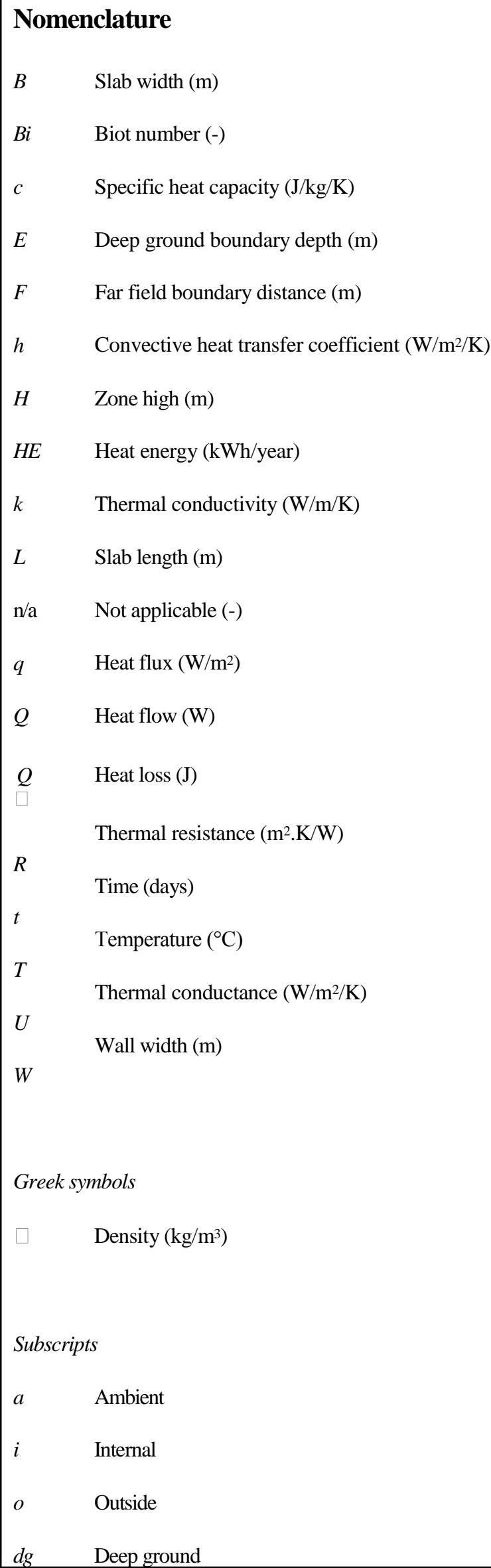




\begin{tabular}{|ll|}
\hline $\begin{array}{l}p \\
*\end{array}$ & Constant pressure \\
Abbreviations & \\
BC & Boundary condition \\
BESTEST & Building energy simulation test \\
CHTC & Convective heat transfer coefficient \\
$C M$ & COMSOL Multiphysics \\
IEA & International energy agency \\
\hline
\end{tabular}

\section{Introduction}

Buildings are complex structures with many constraints due to a complicated geometry and variable boundary conditions. For this reason, specific simulation software for heat and mass calculation in buildings were developed. The room air temperature is influenced by the variations in outdoor conditions such as the temperature, the solar radiation, the overcast sky or the daily use of the room. The room air temperature value influences overall building heat losses, in other words costs, which has to be annually paid for building service. Therefore it is common to use software tools for simulations of the thermal building behaviour to propose the optimal U-wall value or the daily heating scheme.

The energy consumption of the buildings accounts for about $40 \%$ of energy consumption in the European Union in recent years [1], but a reduction of the energy consumption via the additional decrease of the U-wall value in the following days is no more economically optimal. Therefore the actual tendency results in the energy recovery through the heat accumulation [2] or the more effective ventilation control [3].

Publication [4] presents a significant tendency in decreasing the energy consumption using numerical calculations for prediction of internal building environment. As the numerical tools' accuracy has to be validated, the demand for software benchmarking increases.

Three types of tests are recommended to evaluate the accuracy of numerical models in report [5] or further published [6]:

\footnotetext{
- Analytical verifications.

- $\quad$ Comparison with other models (comparative testing).
} 
- $\quad$ Validation with experimental results (experimental validation).

These validation steps serve as directions in validation, testing, and diagnostics to eliminate programming errors which can occur in simulation software.

Additionally, paper [6] splits each of these steps into the verification of the building envelope and the on-site energy generation equipment; and presents the advantages and disadvantages of each validation step.

Several software benchmarks were created in recent years. One of these benchmarks is the Building Energy Simulation Test (BESTEST) provided by the International Energy Agency (IEA) in the Task 34 [7]. The benchmark IEA Task 34 is based on the three-dimensional thermal conduction between the room floor and the external soil. Presented model is specialized especially on long time constants and the heat storage of the ground. In this article, the COMSOL Multiphysics (CM) [8] is validated by three types of tests mentioned above. The validated program is based on the numerical solution of partial differential equations by the finite element method; its usage is wide as can be seen in [9]. Nevertheless, it is not being used very often for building simulations. The application of the CM for building simulations can be found in [10], [11]. The advantage of the $\mathrm{CM}$ consists as well as few other programs in multiphysics simulations and its ability to link with the MATLAB environment [12], [13] for more thorough results processing.

\section{Methods}

The validation of the $\mathrm{CM}$ for its usage for building simulations is divided into three steps, which represent following subsections. First, the numerical simulation results are compared with the analytical solutions. Second, numerically calculated model test cases presented in the Task 34 [7] are compared with the results from the CM. Finally, the behaviour of measured room air temperature is compared with the results from a model based on conduction, convection and radiation created in the CM.

The grid sensitivity for all particular models presented in this work was tested. If the deviation between the results from finer and original grid was larger than $1 \%$, the solution from the model with improved grid was applied.

All created models assume isotropic thermal properties of individual components, which are independent of time and temperature. 


\subsection{Analytical models description}

The numerical and analytical models and the analytical verification are based on the one-dimensional transient heat conduction, which can be found in [14]. The solution of this equation is based on the form of the initial conditions and the Boundary Conditions (BCs). One type of the initial condition was used - the constant temperature - and two types of the BCs were used: the fixed temperature on the model surfaces (the 1 st-type

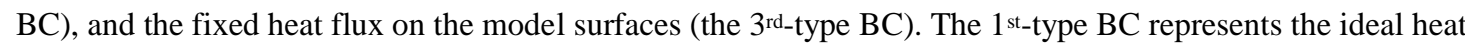
transfer on the phase interface, whereas the second $\mathrm{BC}$ is more natural as it calculates the heat transfer with the finite value of the Convective Heat Transfer Coefficient (CHTC).

The analytical verification by means of the analytical model should provide basic information about detailed solver settings for precise results of verifying software for numerical simulation.

\subsection{Comparative test characterization}

\begin{tabular}{|c|c|c|c|c|c|c|c|c|c|c|c|c|}
\hline$B$ & $L$ & $H$ & $W$ & $\overline{T_{i}}$ & $T_{o}$ & $T_{d g}$ & $E$ & $F$ & $h_{\text {int }} h_{\text {ext }}$ & $c_{p}$ & $\square \square$ & $k$ \\
\hline $\begin{array}{l}{[m]} \\
{[\mathrm{W} / 1}\end{array}$ & $\begin{array}{l}{[m]} \\
/ \mathrm{K}]\end{array}$ & {$[m]$} & {$[m]$} & {$\left[{ }^{\circ} \mathrm{C}\right]$} & {$\left[{ }^{\circ} \mathrm{C}\right]$} & {$\left[{ }^{\circ} \mathrm{C}\right]$} & {$[m]$} & {$[m]$} & {$\left[\mathrm{W} / \mathrm{m}^{2} / \mathrm{K}\right]$} & {$[\mathrm{J} / \mathrm{kg} / \mathrm{K}]$} & $\square \mathrm{kg} / \mathrm{m}^{3}$ & $\square$ \\
\hline 12 & 12 & 2.7 & 0.24 & 30 & Various & 10 & 15 & 15 & 100 & 1800 & 1490 & 1.9 \\
\hline
\end{tabular}

Table 1 Default geometry and physical parameters of test cases specified in Task 34

Six steady-state and eleven transient cases specified in the Task 34 [7] were created in the verifying software. Consequently, its results are compared to the individual test results. Individual test cases are a variation of default model (Case GC30b) whose parameters are depicted in Table 1.

A schematic projection of modelled geometry presenting a conditioned zone on the ground is shown in Fig. 1 and a schematic plain view of the conditioned zone geometry is displayed in Fig. 2 (the conditioned zone floor plan dimensions are $B \times L$ with the wall thickness $W$ ). 


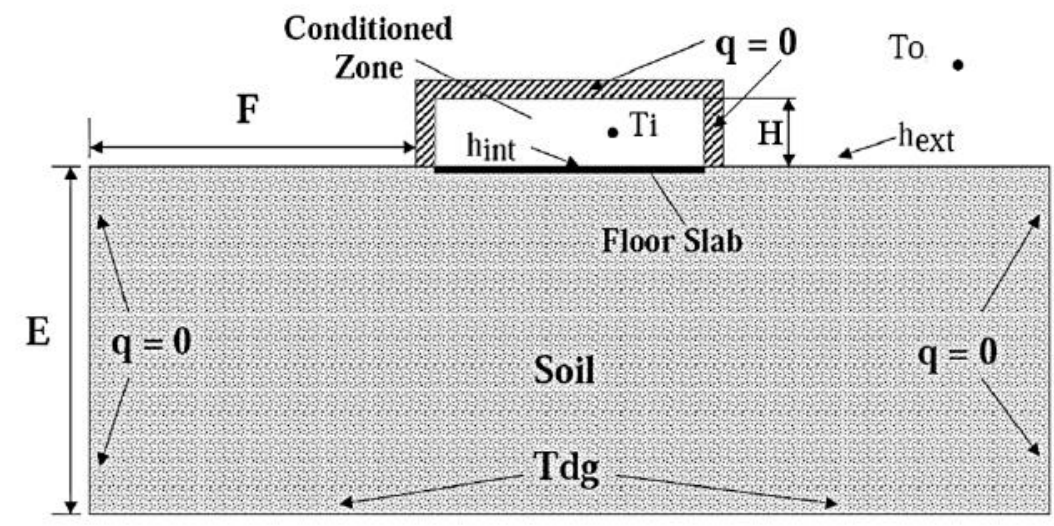

Figure 1 Schematic projection of a model discussed in Task 34 [7]

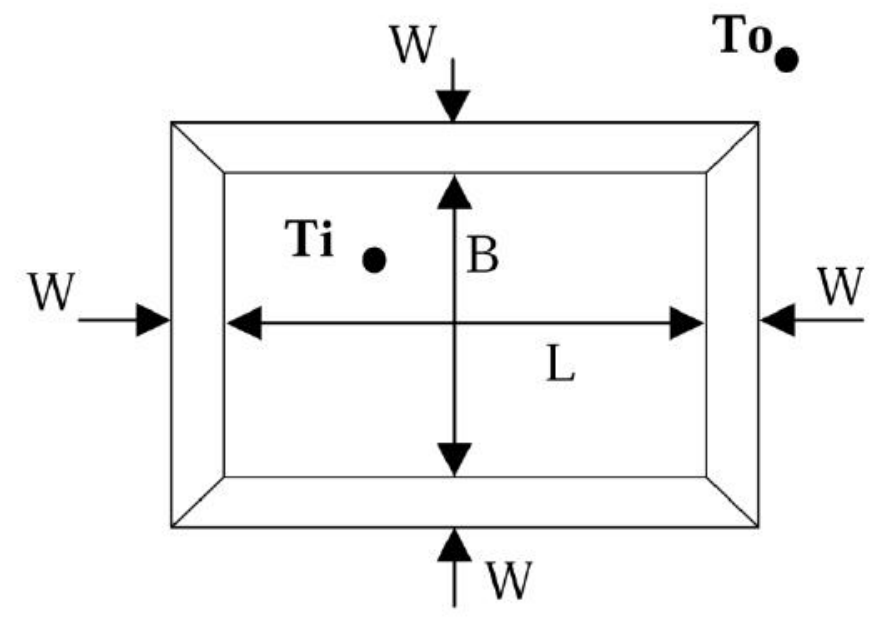

Figure 2 Plain view of conditioned zone geometry [7]

The individual programs validated via this benchmark are at first compared to the analytical solution of the test case GC10a providing the mathematical truth standard. The results of this case are compared to an exact analytically derived solution, while the results of the other test cases are evaluated via developed secondary mathematical truth standard (the standard of accuracy for predicting the system behaviour based on the range of disagreement of a set of closely agreeing verified numerical models or other quasi-analytical solutions, to which other simulations may be compared) [7], which consists of the numerical results from the models applied in the programs Fluent, MATLAB, and TRNSYS.

The approach to building test cases provided in this benchmark is based on the incrementally varying test case parameters, which help diagnose model results differences. 


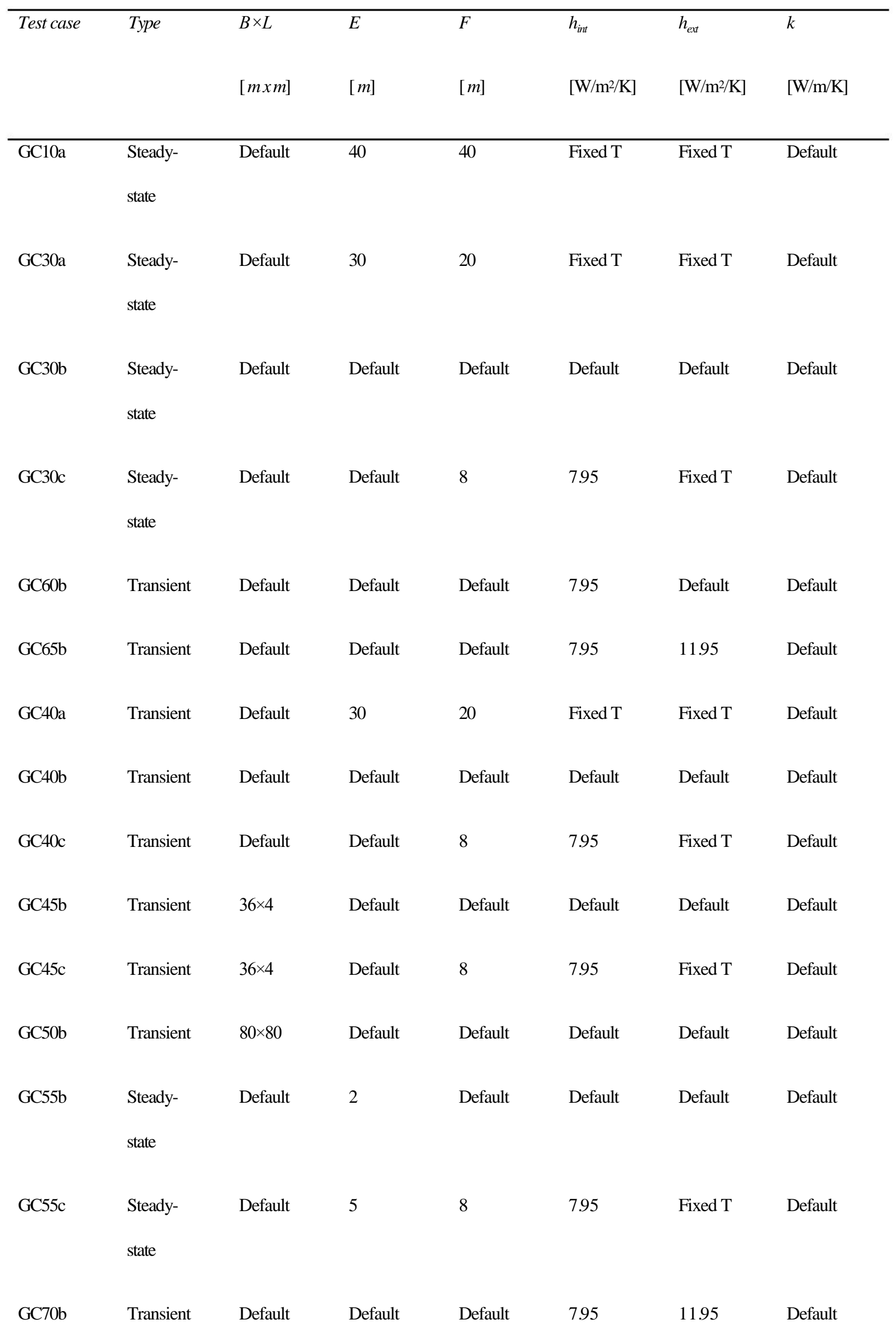




\begin{tabular}{|c|c|c|c|c|c|c|c|}
\hline Test case & Type & $B \times L$ & $E$ & $F$ & $h_{i n t}$ & $h_{e x t}$ & $k$ \\
\hline & & {$[\mathrm{mxm}]$} & {$[m]$} & {$[m]$} & {$\left[\mathrm{W} / \mathrm{m}^{2} / \mathrm{K}\right]$} & {$\left[\mathrm{W} / \mathrm{m}^{2} / \mathrm{K}\right]$} & {$[\mathrm{W} / \mathrm{m} / \mathrm{K}]$} \\
\hline GC80b & Transient & Default & Default & Default & Default & Default & 0.5 \\
\hline GC80c & Transient & Default & Default & 8 & 7.95 & Fixed $\mathrm{T}$ & 0.85 \\
\hline
\end{tabular}

Table 2 Specific test case parameters

Presented cases drive the floor conduction based on the temperature deviation between the zone air temperature and the ground temperature. The test cases calculate with the fixed deep ground temperature, but different BCs on the slab and ground surfaces - the fixed temperature, and the high or ordinary CHTC - are used. The values of specific model parameters that vary from the default values are described in Table 2.

Test cases presented in the Task 34 are characterized by the fixed domain temperature in conditioned domain which is impossible to be modelled directly in the CM. It is possible to set the fixed temperature value only on boundaries. The conditioned zone is therefore modelled with the fixed temperature on internal wall surfaces.

\subsection{Experiment description}

The three-dimensional model geometry based on the combination of conduction, convection and radiation and its visualization is shown in Fig. 3. The most important model parts are (numbers in bracket refer to model parts in Fig. 3): the internal walls consisting of the Porotherm 300 (1); the external wall which is composed of the Porotherm 400 (2) and the reinforced concrete (3); the polystyrene insulation on the external wall (4); the windows (5); the roof composed of the polystyrene insulation (6) and the concrete (7); the wooden door (8); and the concrete floor (9).

The dimensions of the laboratory depicted in Figs. 3 and 4 are $7.2 \times 8.7 \times 3 m$ and the experiment took almost 19 days. The temperature behaviours were measured $1.3 m$ above the floor in a point MP1, $0.84 m$ in a point MP2 and $1.62 \mathrm{~m}$ in a point MP3. The positions are highlighted in Fig. 4. The temperature was measured by the globe and the NiCr thermometer in the point MP1 and by the NiCr thermometers in the points MP2 and MP3. 


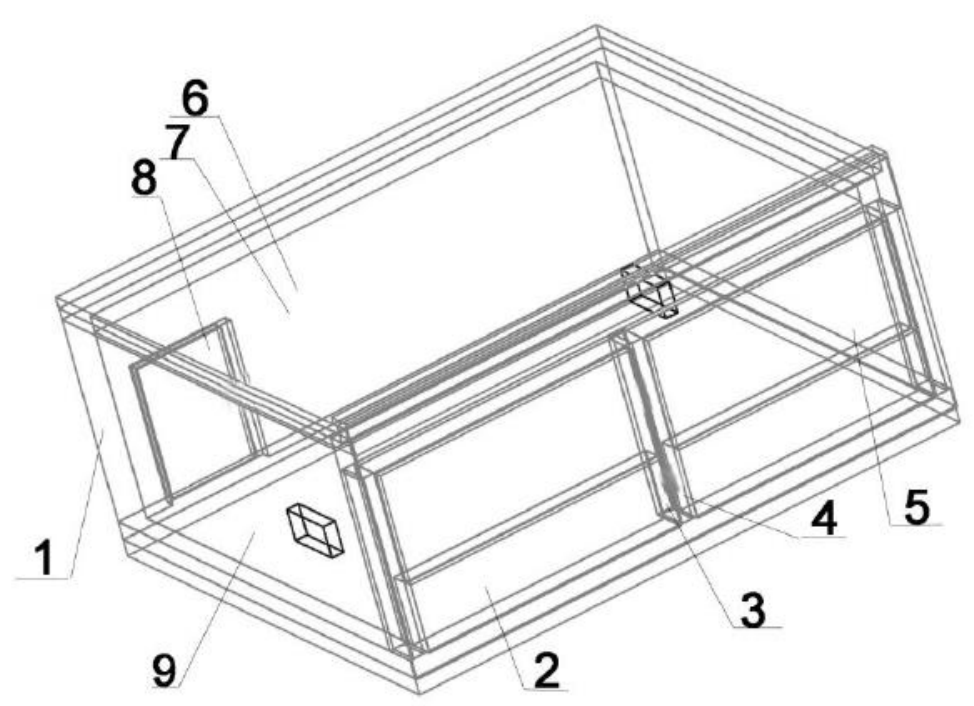

Figure 3 Geometry of the room model for experimental validation

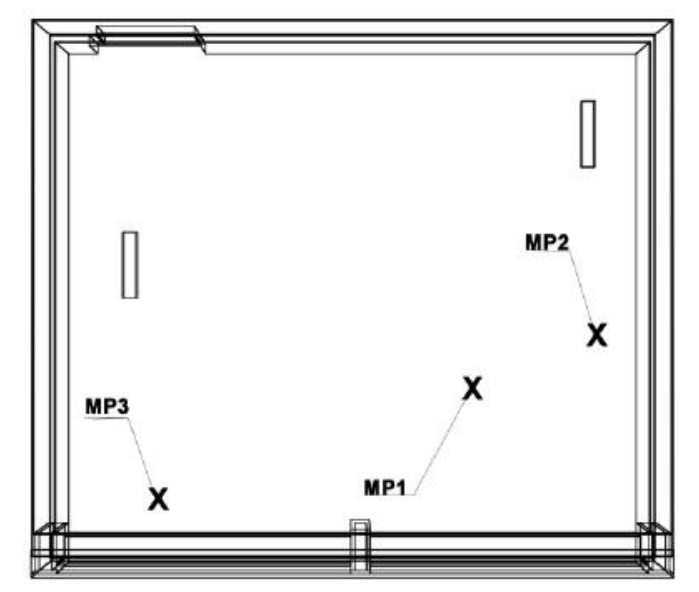

Figure 4 The room plan with highlighted measuring points

The room is located in the middle of the top floor of an occupied building, which means that it has one wall and roof influenced by the external weather conditions. The rest of the room walls adjoin with the internal areas with the thermal conditions very similar to the room temperature. The thermal parameters of model walls taken from the building plan are shown in Table 3. The wall U-values were not experimentally measured in spite of the possible risk in disagreements between theoretical and realistic values [15]. Internal walls have the minimal heat resistance; however there is a minimal heat transfer through these walls because of the small temperature difference between internal areas. The heat flux via these walls is only about $1.6 \%$ of the overall room heat losses thus it is practically insignificant for the model calculation as you can see in publication [16]. The majority of the heat transfer goes through the external wall and the windows. Therefore, the heat transfer calculation is very sensitive for the value of the CHTC on these surfaces. 


\begin{tabular}{|c|c|c|c|c|}
\hline Material & $\begin{array}{l}W \\
{[m]}\end{array}$ & $\begin{array}{c}k \\
{[W / m / K]}\end{array}$ & $\begin{array}{c}R \\
{\left[m^{2} \cdot K / W\right]}\end{array}$ & $\begin{array}{c}U \\
{\left[W / m^{2} / K\right]}\end{array}$ \\
\hline Porotherm 300 & 0300 & 0.250 & 1200 & 0.833 \\
\hline Porotherm 400 & 0.400 & 0.150 & 2.670 & 0.375 \\
\hline Polystyrene (external wall) & 0.050 & 0.034 & 1.471 & 0.648 \\
\hline Polystyrene (roof) & 0280 & 0.034 & 8.235 & 0.121 \\
\hline Concrete (roof) & 0.180 & 1.430 & 0.126 & 7.940 \\
\hline Concrete (floor) & 0290 & 1.430 & 0.203 & 4.931 \\
\hline Reinforced concrete with polystyrene insulation & 0550 & 1.430 & 0.385 & 2.600 \\
\hline Reinforced concrete insulation & 0.100 & 0.034 & 2.941 & 0340 \\
\hline Window & 0.012 & 0.024 & 0500 & 2.000 \\
\hline
\end{tabular}

Table 3 Construction parameters used for experimental validation

The data were measured in December 2010 and January 2011 in Zlín, The Czech Republic. The room was heated and cooled in several cycles; electric convector heaters were used to control the rising heat power precisely. The total heat power of electric heaters was $5 \mathrm{~kW}$. The room temperature fluctuated during the experiment period in a range from $14{ }^{\circ} \mathrm{C}$ to $30^{\circ} \mathrm{C}$.

\section{Results}

\subsection{Analytical program verification}

Domain and boundary parameters were set according to the section 2.1 on rectangular wall geometry. The preliminary numerical simulation results revealed that it is not possible to use default program settings to get the precise simulation results - it is important to set at least 10 times smaller relative and absolute errors in solver settings, and it is also necessary to create a mesh with very fine elements. As a consequence, the swept mapped mesh with 20 layers was generated. 
The comparison of the numerical model and analytical solution is presented in Fig. 5 and 6 . The figures show the temperature profile from the half of the single layer wall considering the model symmetry. The analytical results are represented by solid lines and the outputs from numerical models are depicted by dashed lines. The temperature distribution in four different times is compared. It is obvious that the temperature drop caused by the

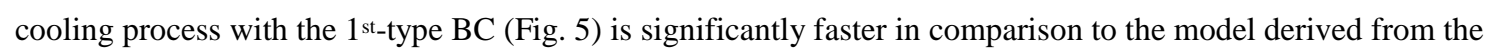
3rd-type BC (Fig. 6). It is caused by the infinite value of the CHTC, which can be derived from the relation

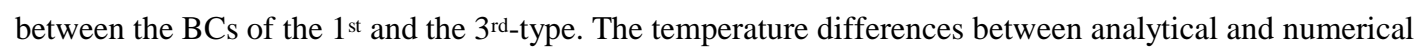
models in the dimensionless wall profile are in the order of tenths of a degree Celsius.

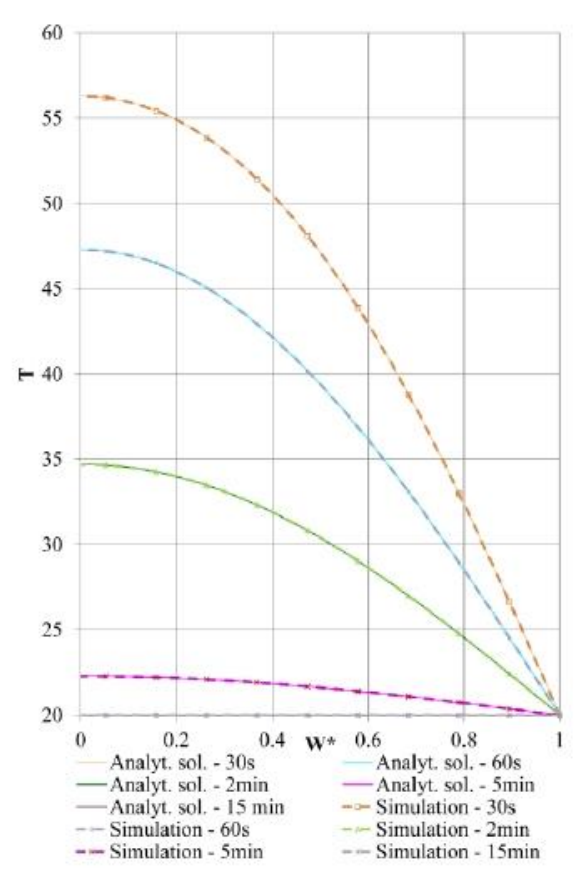

Figure 5 Temperature distribution of analytical and numerical model with 1st-type BC 


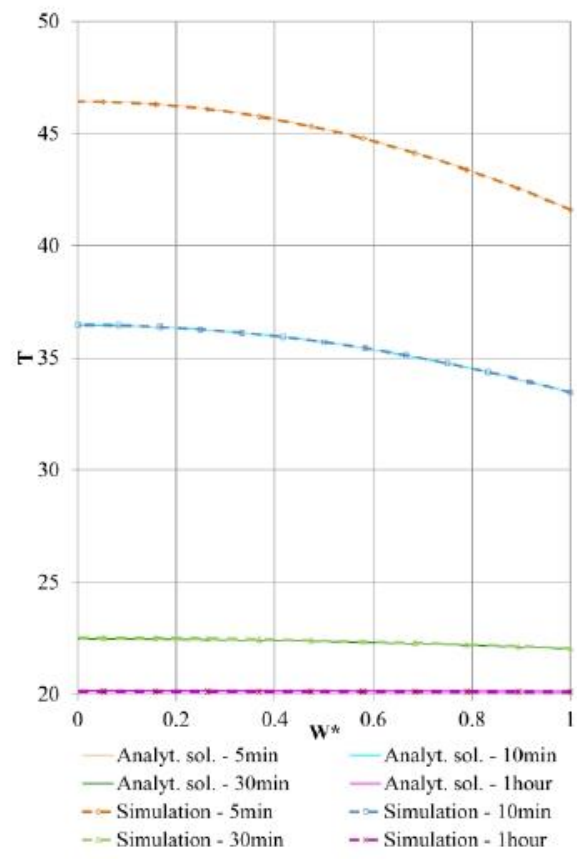

Figure 6 Temperature distribution of analytical and numerical model with $3^{\text {rd-type BC }}$

\subsection{Validation via Analytical Verification and Comparative Testing}

The steady-state test cases comparison of the $\mathrm{CM}$ with the results from the analytical solution and nine validated simulation software are shown in Fig. 7. Particular bars represent the calculated heat flow through the room slab of six steady-state test cases. Although no evident discrepancies in Fig. 7 are visible; the sensitivity plot for a close look to particular steady-state test cases' results is presented in Fig. 8.

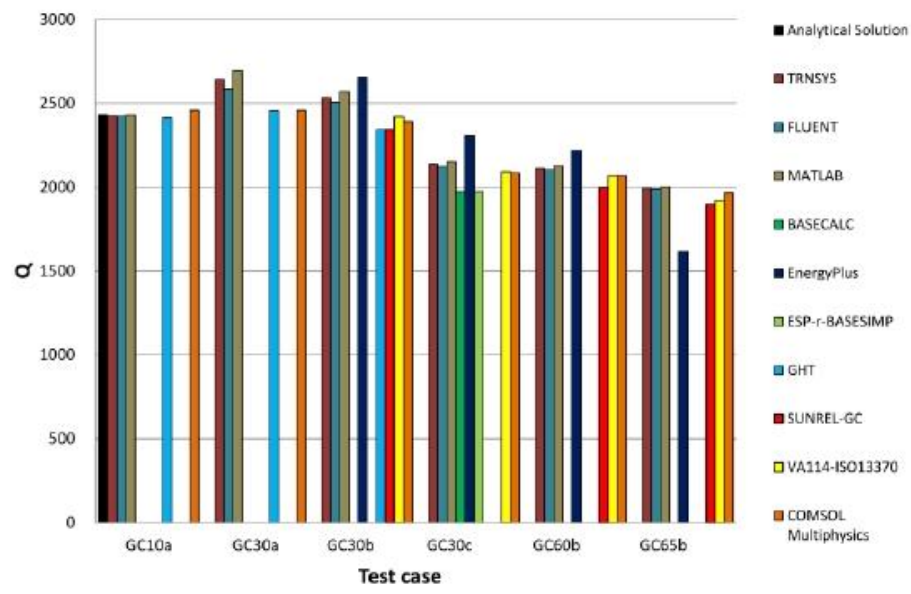

Figure 7 Comparison of CM and already validated software results - steady-state cases 
The sensitivity comparison of steady-state test cases indicates the underestimating CM results and the overestimating EneryPlus results. The largest CM differences mostly occur in the sensitivity juxtapositions based on a changed value of the CHTC.

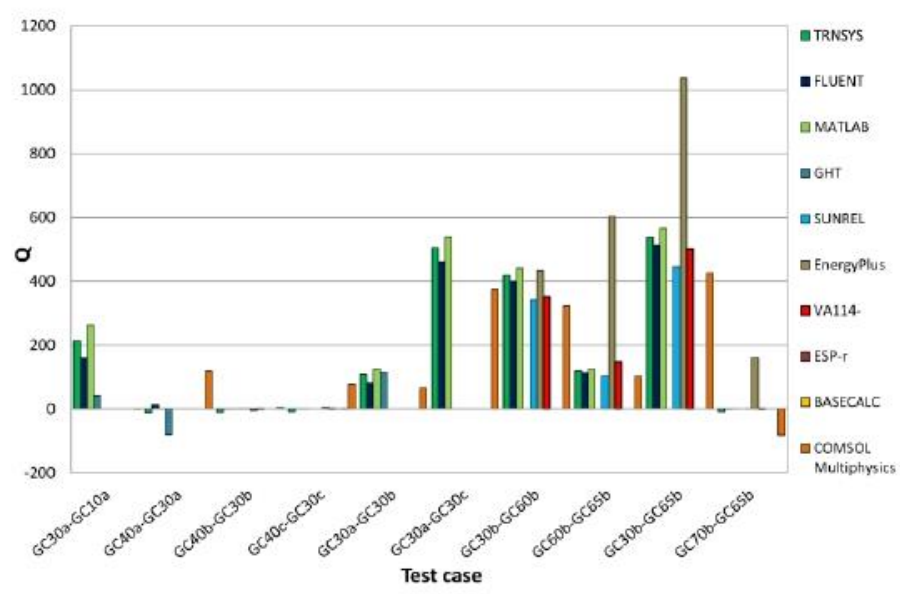

Figure 8 Sensitivity comparison of steady-state test cases

The closer scrutiny of values presented in Fig. 7 and 8 can be seen in Table 4, where the statistical evaluation of these heat flows is evaluated. The statistical evaluation is calculated for each steady-state test case as a deviation between the $\mathrm{CM}$ results and the mean value of the secondary mathematical truth standard, which represents the results values from the programs Fluent, MATLAB, and TRNSYS. It can be concluded from steady-state cases that the CM mostly underestimates the heat flow between the conditioned zone and the ground. The mean value of the absolute relative deviation of the heat flows calculated by the CM is $3.33 \%$. Two largest deviations occur in the test cases GC30a (-6.88 \%) and GC30b (-5.66\%). The high CHTC value on the internal zone surface as well as on the ground surface is typical for these test cases. The similar model setting is also used for the test case GC10a; and unexpectedly, this test is the only one calculated with the positive heat flow deviation.

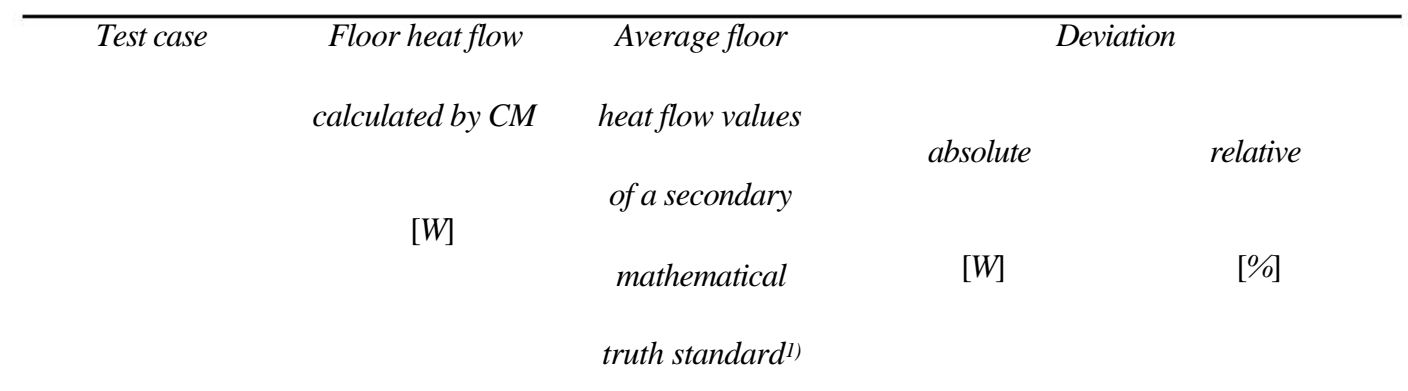




\begin{tabular}{|c|c|c|c|c|}
\hline \multirow[t]{2}{*}{ Test case } & \multirow{2}{*}{$\begin{array}{c}\text { Floor heat flow } \\
\text { calculated by CM } \\
{[W]}\end{array}$} & \multirow{2}{*}{$\begin{array}{c}\text { Average floor } \\
\text { heat flow values } \\
\text { of a secondary } \\
\text { mathematical } \\
\left.\text { truth standard }{ }^{l}\right) \\
{[W]}\end{array}$} & \multicolumn{2}{|c|}{ Deviation } \\
\hline & & & $\begin{array}{c}\text { absolute } \\
{[W]}\end{array}$ & relative \\
\hline GC10a & 2459 & 2428 & 31 & 129 \\
\hline GC30a & 2459 & 2641 & -182 & -6.88 \\
\hline GC30b & 2392 & 2536 & -144 & -5.66 \\
\hline GC30c & 2084 & 2138 & -54 & -2.54 \\
\hline GC60b & 2069 & 2115 & -46 & -2.17 \\
\hline GC65b & 1967 & 1996 & -29 & -1.47 \\
\hline
\end{tabular}

1) Average value calculated by Fluent, MATLAB, and TRNSYS

Table 4 Steady-state test case deviations calculated by $\mathrm{CM}$

The overall mean deviations and their standard deviations of calculated heat flows from steady-state test cases made by six programs, which have been already validated via this benchmark and with the CM, are shown in Table 5. The overall mean deviation values are calculated as the deviations of a particular program mean deviation, which are compared with the secondary mathematical truth standard. Thus values presented in this table represent a disagreement with this standard, which is calculated as the mean value of the Fluent, MATLAB, and TRNSYS models. The notes below the table refer to test cases which were calculated in the specific program. It is evident that the mean deviation of verifying software is slightly worse than the value calculated by the VA114-ISO13370 method, but significantly less than other overall mean deviations. The standard deviation cannot be calculated in the ESP-r-BASESIMP or the BASECALC because only one test case was modelled in this software. 


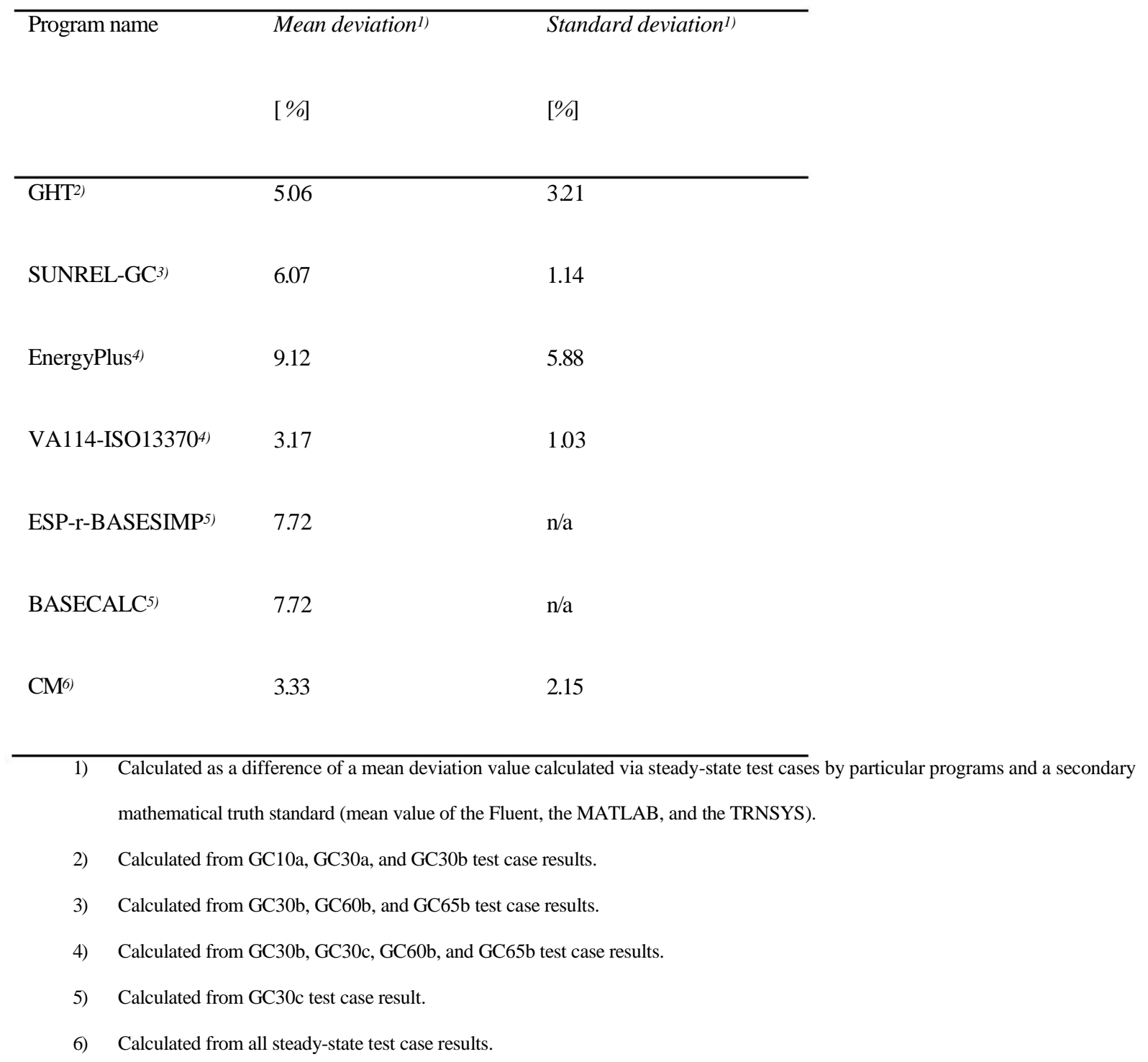

Table 5 Comparison of six validated software with the CM - steady-state cases

The transient test cases comparison of the $\mathrm{CM}$ with the results from nine validated simulation software is shown in Fig. 9. Particular bars represent the heat energy calculated as a sum of heat flows through the room slab during the one year period. Some discrepancies of the EnergyPlus program in the test cases GC50b and GC55b are evident. The sensitivity evaluation is presented in Fig. 10, and more detailed comparison shows Table 6. 


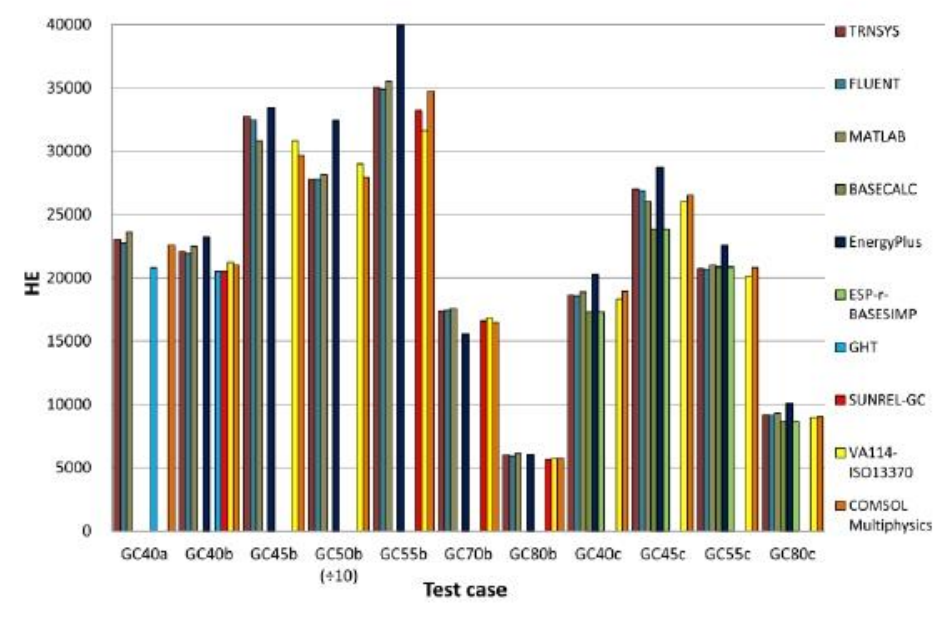

Figure 9 Comparison of CM and already validated software results - transient cases

The sensitivity comparison of the transient test cases shows again a small underestimated result, but also an evident CM result errors in the CHTC value sensitivity comparison (GC40a-GC40b), sensitivity to slab aspect ratio (GC45b-GC40b), and comparison of the test case based on normal and large slab area (GC40b-GC50b).

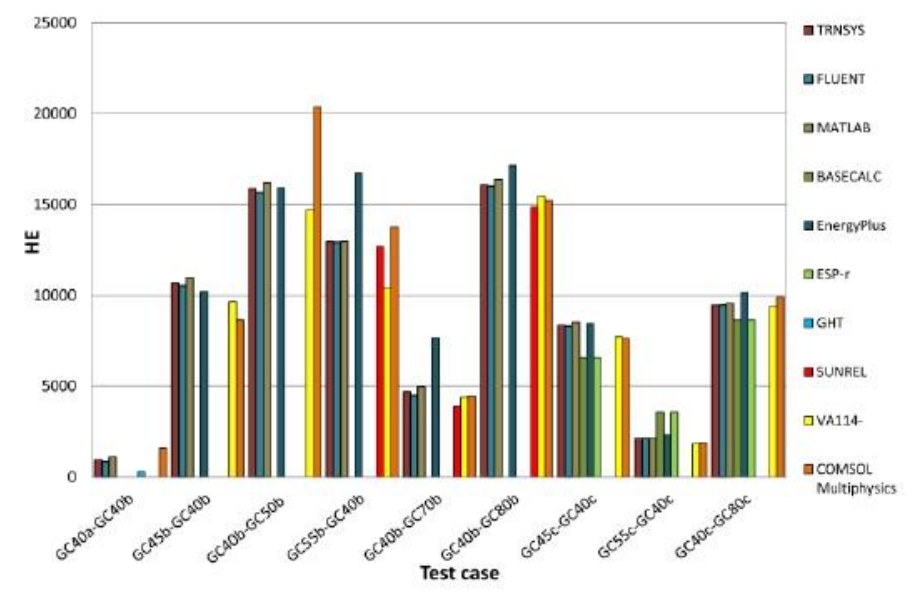

Figure 10 Sensitivity comparison of transient test cases

Table 6 presents the statistical evaluation of transient test cases. The deviations of transient test cases are again mostly negative as in steady-state test cases. The largest difference arises in the case GC45b, which is based on the usage of high value of the CHTC on the internal and external model boundaries just like on the high perimeter heat transfer fraction. The noticeable fact is that the third and fourth largest deviations are also modelled with these BCs.

Test case Floor heat flow Average floor Deviation




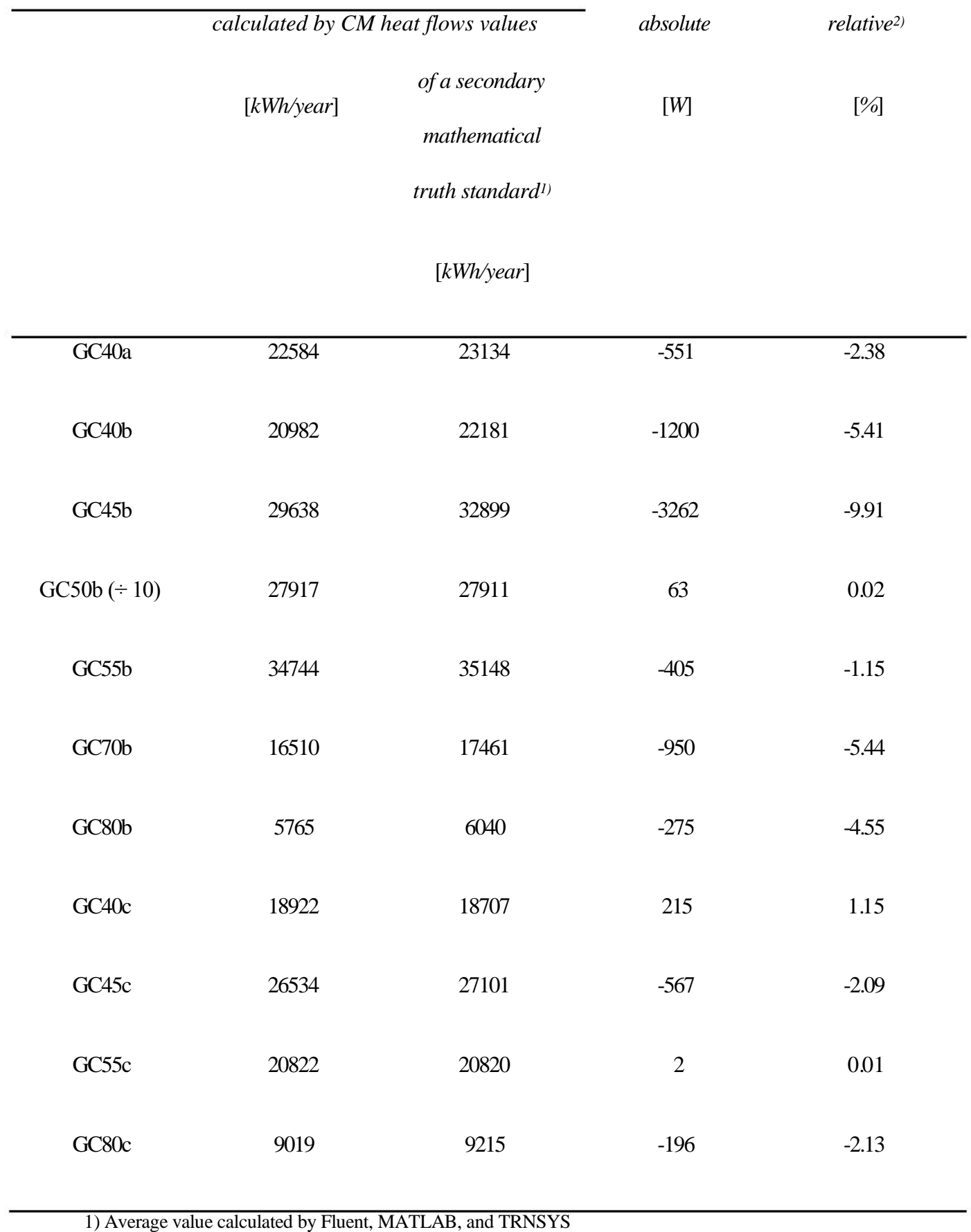

1) Average value calculated by Fluent, MATLAB, and TRNSYS

Table 6 Transient test case deviations calculated by CM

The mean deviations and its standard deviations of calculated heat flows from transient test cases from seven programs which are compared with the secondary mathematical truth standard are presented in Table 7 . The values presented in this table represent the disagreement with this standard. The notes below the table refer to test cases which were calculated in the specific program. It is evident that the minimal value of the mean difference in comparison to the secondary mathematical truth standard is calculated by the CM. The VA114ISO13370 method calculated the transient test with higher mean deviation about 1.5 percentage points; most of 
compared programs has the mean deviation larger than $6 \%$. The mean deviation of the $\mathrm{CM}$ results from transient test cases is about 0.6 percentage points smaller in comparison with its steady-state test case mean deviation.

To conclude the transient test cases, the evaluated software is able to get similar results in comparison to the Fluent, MATLAB, and TRNSYS which represent the secondary mathematical truth standard.

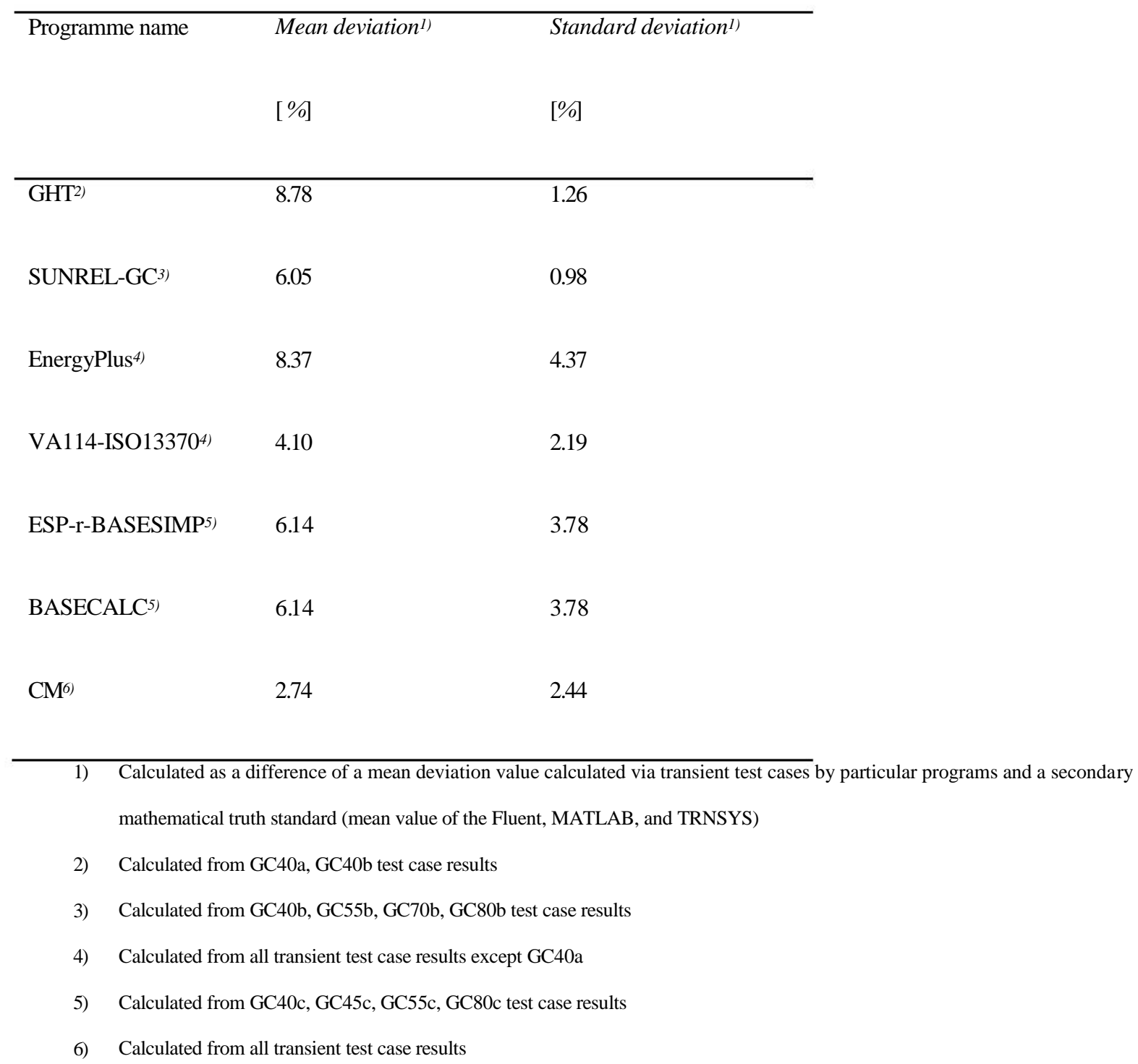

Table 7 Confrontation of six validated software with CM - transient cases

\subsection{Experimental program validation}

Boundary

$Q$

$[J]$ 
Boundary

$Q$

$[J]$

External wall with windows

Roof

Floor and internal walls

Table 8 Boundary heat losses

The air velocity was not measured during the experiment with reference to only local information, but the model assumes this parameter with the value $0.1 \mathrm{~m} . \mathrm{s}^{-1}$, which is commonly recommended value for the indoor air velocity [17].

Data presented in Table 8 depict the sum of heat flows over three types of boundaries. The floor and internal walls are count altogether, because they both border with internal building zones. As expected, the majority $(94.0 \%)$ of heat losses goes through the external wall with windows, about $4.3 \%$ via the roof, and the internal walls with the floor have the minimal influence on the room heat transfer (1.7\%). Subsequently, this nonuniform distribution of the heat transfer isolated the high model sensitivity to the CHTC value on the external wall and windows surfaces. An unexpected model disagreement in the cooling down phases occurred before realization of that situation. The preliminary simulation results contain the mean deviation about $1.9^{\circ} \mathrm{C}$. The preliminary model was calculated with the fixed CHTC value $2.5 \mathrm{~W} \cdot \mathrm{m}^{-2} \cdot \mathrm{K}^{-1}$ as the majority of the European standards recommended, e.g. [18].

The more detailed investigation confirmed the presumption of the influence of the CHTC value to the mean deviation between the simulation results and measured data. Therefore, the model was updated and the CHTC value was calculated in every simulation time step by actual temperature conditions. The minimal and the maximal value of the CHTC calculated during the simulation cycle were $2 \mathrm{~W} \cdot \mathrm{m}^{-2} \cdot \mathrm{K}^{-1}$ and $4.5 \mathrm{~W} \cdot \mathrm{m}^{-2} \cdot \mathrm{K}^{-1}$, which indicates certain underestimation of the calculation of the CHTC value via European standards.

The simulation results with the variable CHTC in comparison to the measured temperature data are shown in Fig. 11. The plot shows that the simulated and measured data are similar especially in the second half of the experiment with minor differences mostly in cooling phases. The cooling phases show that the lines have the 
same trend, but the decreasing rate of temperature variation is slightly different even with the variable value of the CHTC. This can be caused by the heat accumulation in the additional room equipment such as furniture, desks or chairs, which were not taking into account in the room model. The minor influence on the simulation results may also have the specific CHTC value in the corners.

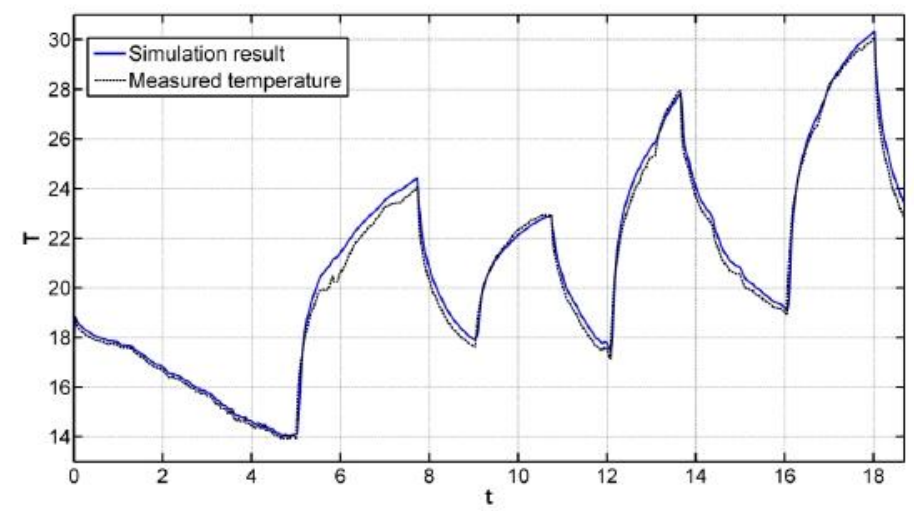

Figure 11 Comparison of temperature behaviour

The following two figures show data presented in Fig. 11 in the form of heat fluxes transferred between the laboratory and outside areas. The figures compare the zone load calculated from measured and simulated temperature behaviour to get a relative energy cost effect. Values of the heat flux are presented in Fig. 12, while the values in watts (absolute values) and percentages (relative values) of the heat flux differences are displayed in Fig. 13.

The behaviours presented in Fig. 12 document the high model accuracy for loads, which correlates more directly with energy use than comparing temperatures. The increasing outgoing heat flux in the first part of the plot is caused by the external temperature drop from approximately $12^{\circ} \mathrm{C}$ to $-10^{\circ} \mathrm{C}$ between the first and fourth day.

The data presented in Fig. 13 highlights heat flux differences. The left y-axis shows the absolute value of the difference and the right y-axis demonstrates the relative difference. The mean value of the absolute heat flux difference presented in this figure is $1.39 \%$. The most significant heat flux differences occur at the end of the free cooling phases. 


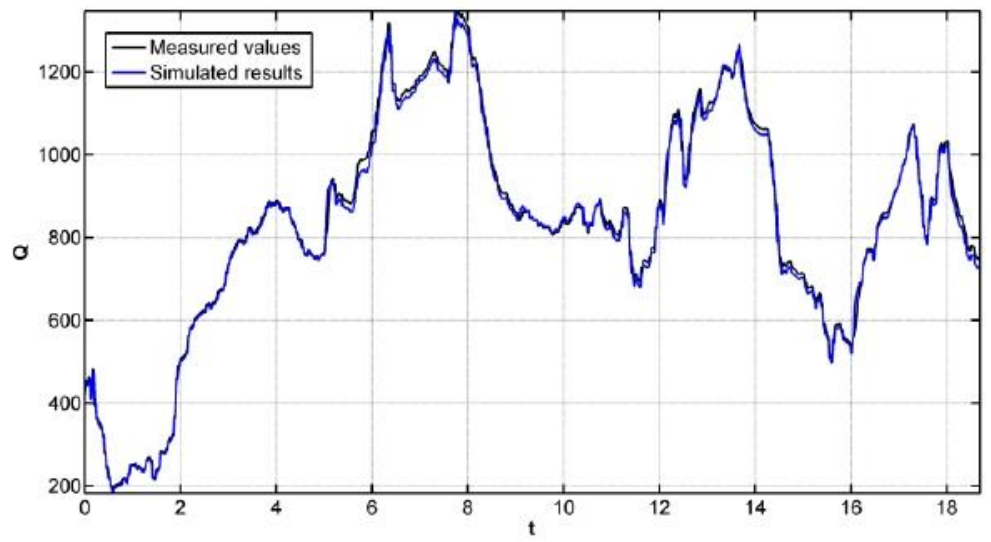

Figure 12 Comparison of heat flux behaviour

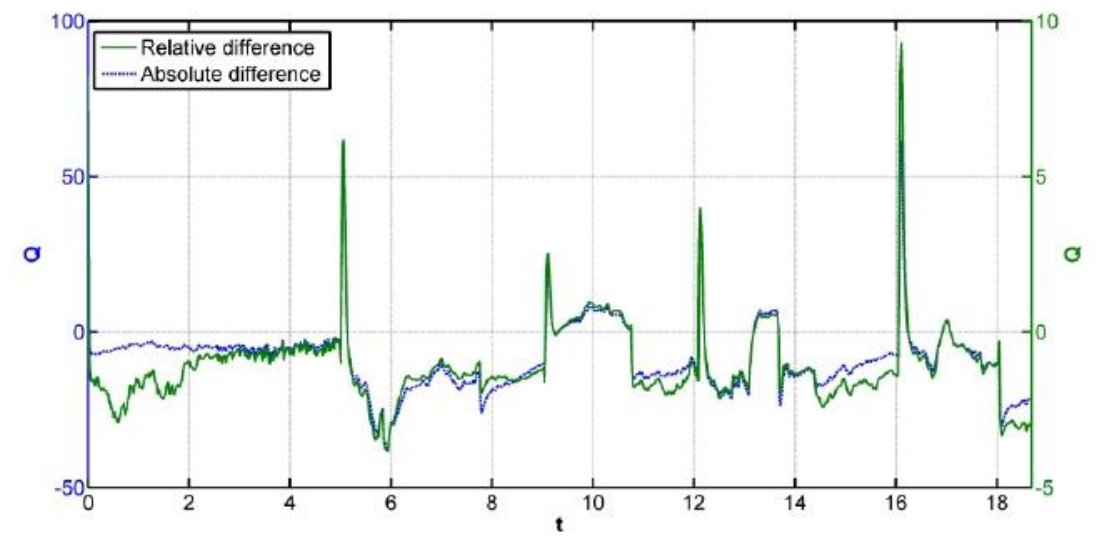

Figure 13 Heat flux difference

\section{Conclusion}

The comparison of the CM with the analytical solution emphasizes two important facts:

- It is necessary to set the numerical solver error tolerance to at least 10 times smaller value in comparison to its default value.

- Models have to be calculated with a very fine mesh to decrease the numerical model error below $1 \%$.

Therefore it can be concluded that the numerical calculation of the heat transfer will be in excellent agreement with the analytical solution only if the numerical solver is set properly.

The CM was used to model the steady-state and the transient ground-coupling models specified in the IEA

BESTEST Task 34 [7]. The results for seventeen models were compared to the secondary mathematical truth 
standard and programmes, which were already evaluated by this benchmark. The results' similarity of the CM with this standard indicates the underestimation of evaluated programme results. The mean difference of the CM is the second lowest in the comparison of steady-state test cases and the lowest in the comparison of transient test case results.

The results of the room model created in the CM were consequently compared to the measured data. The most sensitive parameter is the value of the CHTC, which cannot be set as constant according to values recommended in the European standard [18], but have to be calculated in particular time steps. The simulation results of the temperature and the heat flux behaviours are close to the measured data. In general, the model accuracy is sufficient with the mean heat flux difference $1.39 \%$.

The future work is the programme verification via more complex analytical benchmark [20] and the test cases of the ASHRAE Standard 140-2011 [21].

\section{Acknowledgements}

The article was supported by the European Regional Development Fund under the Project CEBIA-Tech No.

CZ.1.05/2.1.00/03.0089, and by the Internal Grant Agency at Tomas Bata University in Zlín, No.

IGA/FAI/2012/003 and IGA/FAI/2013/001.

\section{References}

[1] Eichhammer W. Study on the Energy Savings Potentials in EU Member States, Candidate Countries and EEA Countries, Fraunhofer-Institute for Systems and Innovation Research. Karlsruhe, 2009.

[2] D. Heim, Isothermal storage of solar energy in building construction, Renew Energy 35 (2010) 788-96.

[3] S. J. Emmerich, B. Polidoro, J. W. Axley, Impact of adaptive thermal comfort on climatic suitability of natural ventilation in office buildings, Energy and Build. 43 (2011) 2101-7.

[4] A.W.M. van Schijndel, H.L. Schellen, J.L.Wijffelaars, K. van Zundert, Application of an integrated indoor climate, HVAC and showcase, Energy and Build. 40 (2008) 647-53.

[5] R. Judkoff, J. Neymark, International Energy Agency Building Energy Simulation Test (BESTEST) and Diagnostic Method, National Renewable Energy Laboratory, Golden, 1995.

[6] R. Judkoff, J. Neymark, Model Validation and Testing: The Methodological Foundation of ASHRAE Standard 140, National Renewable Energy Laboratory, Golden, 2006. 
[7] J. Neymark, R. Judkoff, I. Beausoleil-Morrison, A. Ben-Nakhi, M. Crowley, M. Deru, R. Henninger, H. Ribberink, J. Thornton, A. Wijsman, M. Witte, International Energy Agency Building Energy Simulation Test and Diagnostic Method (IEA BESTEST) - In-Depth Diagnostic Cases for Ground Coupled Heat Transfer Related to Slab-On-Grade Construction; National Renewable Energy Laboratory, Golden, 2008

[8] COMSOL - Multiphysics Modeling and Simulation Software. Multiphysics Modeling and Simulation Software; 2011. http://www.comsol.com.

[9] W. B. J. Zimmerman, Multiphysics Modelling with Finite Element Methods. in: A. Guran (Ed.), World Scientific Publishing Co. Pte. Ltd., Singapore, 2006.

[10] A. W. M. van Schijndel, H. L. Schellen, M. H. de Wit, Improved HVAC operation to preserve a church organ, Build. and Environ. 44 (2009) 156-68.

[11] J. van Schijndel, Integrated Modeling using MatLab, Simulink and COMSOL: with heat, air and moisture applications for building physics and systems, PhD thesis, Eindhoven University of Technology, Eindhoven, NL, 2008.

[12] Z. Huang, P. P. Conway, R. C. Thomson, A. T. Dinsdale, J. A. J. Robinson, A computational interface for thermodynamic calculations software MTDATA, Computer Coupling of Phase Diagrams and Thermochemistry 32 (2008) 129-34.

[13] L. Wissmeier, D. A. Barry, I. R. Phillips, Predictive hydrogeochemical modelling of bauxite residue sand in field conditions, J. of Hazard. Mater. 191 (2011) 306-24.

[14] J. H. Lienhard IV, J. H. Lienhard V, A heat transfer textbook. 4th edition. Phlogiston Press, Cambridge, 2003.

[15] J. Neymark, P. Girault, G. Guyon, R. Judkoff, R. LeBerre, J. Ojalvo, P. Reimer, The "ETNA BESTEST" empirical validation data set, Montreal, 2005.

[16] V. Gerlich, Modelling of Heat Transfer in Buildings. In: Proceedings of 25th European Conference on Modelling and Simulation ECMS 2011, Krakow, 2011.

[17] J. R. Girman, Simple Modeling to Determine Appropriate Operating Conditions for Emission Testing in Small Chambers, in: Niren L. Nagda (Ed.), American Society for Testing and Materials, Philadelphia, 1993.

[18] EN ISO 6946, Building components and building elements - Thermal resistance and thermal transmittance - Calculation method, 2007. 
[19] J. D. Spitler, S. J. Rees, X. Dongyi, Development of an analytical verification test suite for whole building energy simulation programs - building fabric, ASHRAE 1052-RP, 2001

[20] ANSI/ASHRAE Standard 140-2004, Standard Method of Test for the Evaluation of Building Energy Analysis Computer Programs, American Society of Heating, Refrigerating, and Air-Conditioning Engineers, Atlanta, 2011. 
Figure 1 Schematic projection of a model discussed in Task 34 [7]

Figure 2 Plain view of conditioned zone geometry [7]

Figure 3 Geometry of the room model for experimental validation …................................................. 9

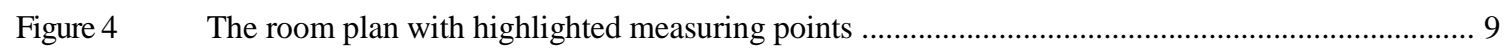

Figure 5 Temperature distribution of analytical and numerical model with 1 st-type BC........................... 11

Figure $6 \quad$ Temperature distribution of analytical and numerical model with 3 rd-type BC .......................... 12

Figure $7 \quad$ Comparison of CM and already validated software results - steady-state cases.......................... 12

Figure $8 \quad$ Sensitivity comparison of steady-state test cases .............................................................. 13

Figure $9 \quad$ Comparison of $\mathrm{CM}$ and already validated software results - transient cases............................. 16

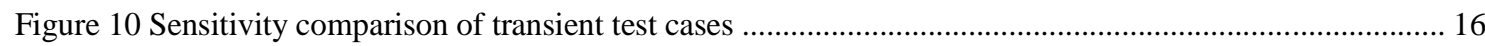

Figure 11 Comparison of temperature behaviour................................................................................ 20

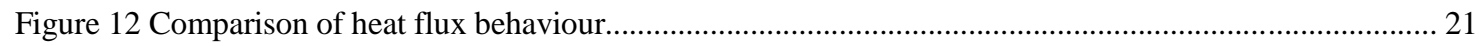

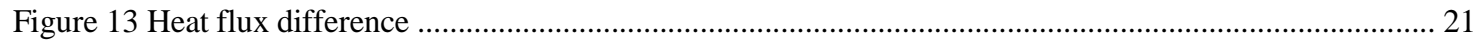

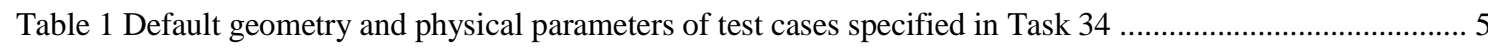

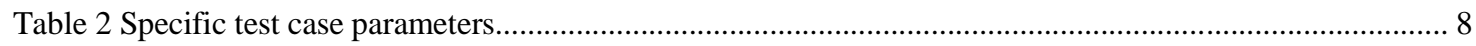

Table 3 Construction parameters used for experimental validation .............................................................. 10

Table 4 Steady-state test case deviations calculated by CM .................................................................... 14

Table 5 Confrontation of six validated software with the CM - steady-state cases ......................................... 15

Table 6 Transient test case deviations calculated by CM..................................................................... 17

Table 7 Confrontation of six validated software with CM - transient cases.................................................. 18

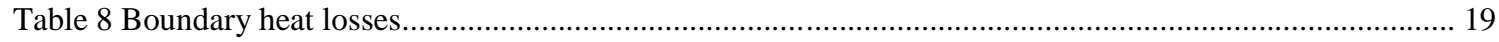




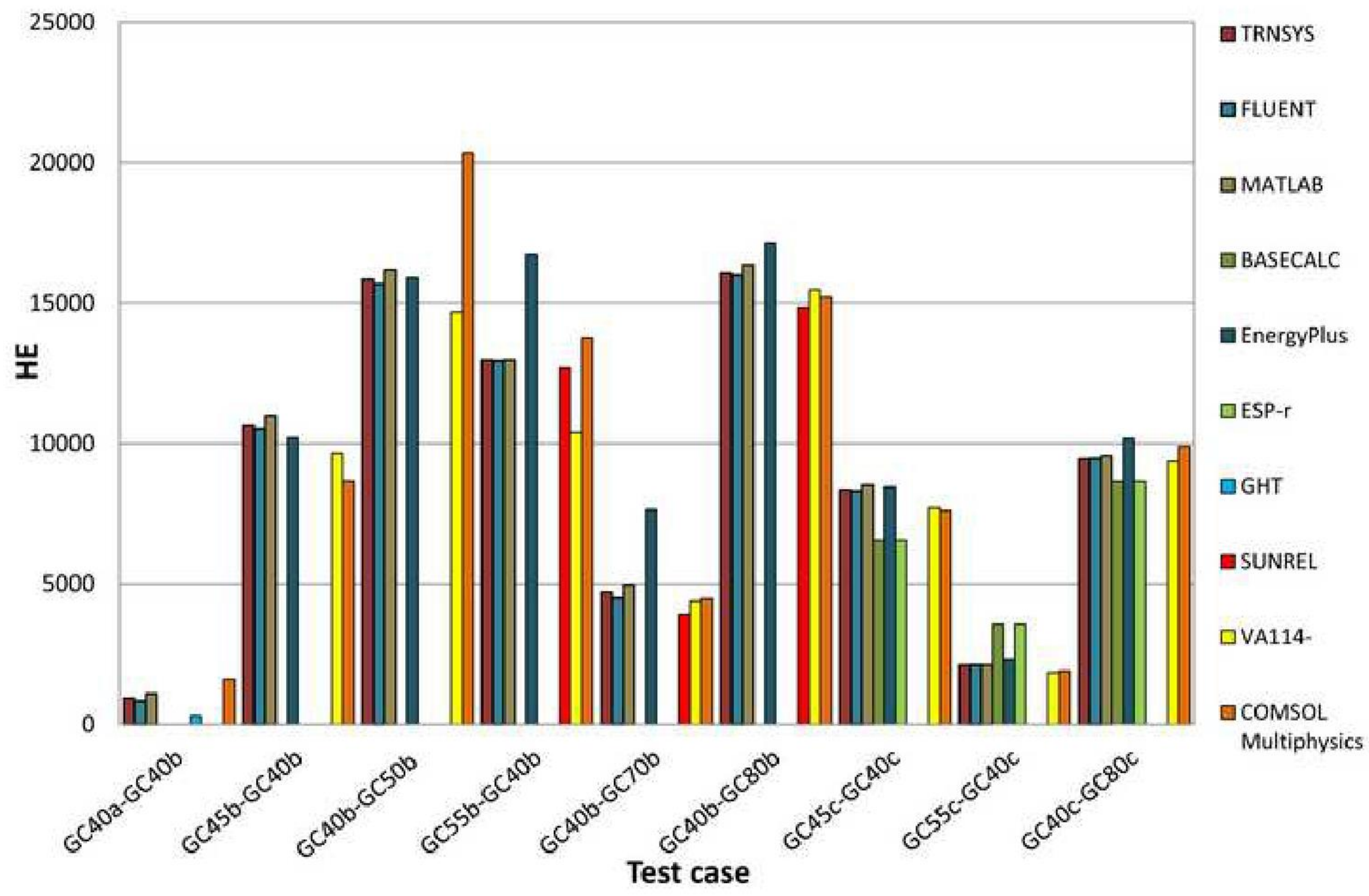




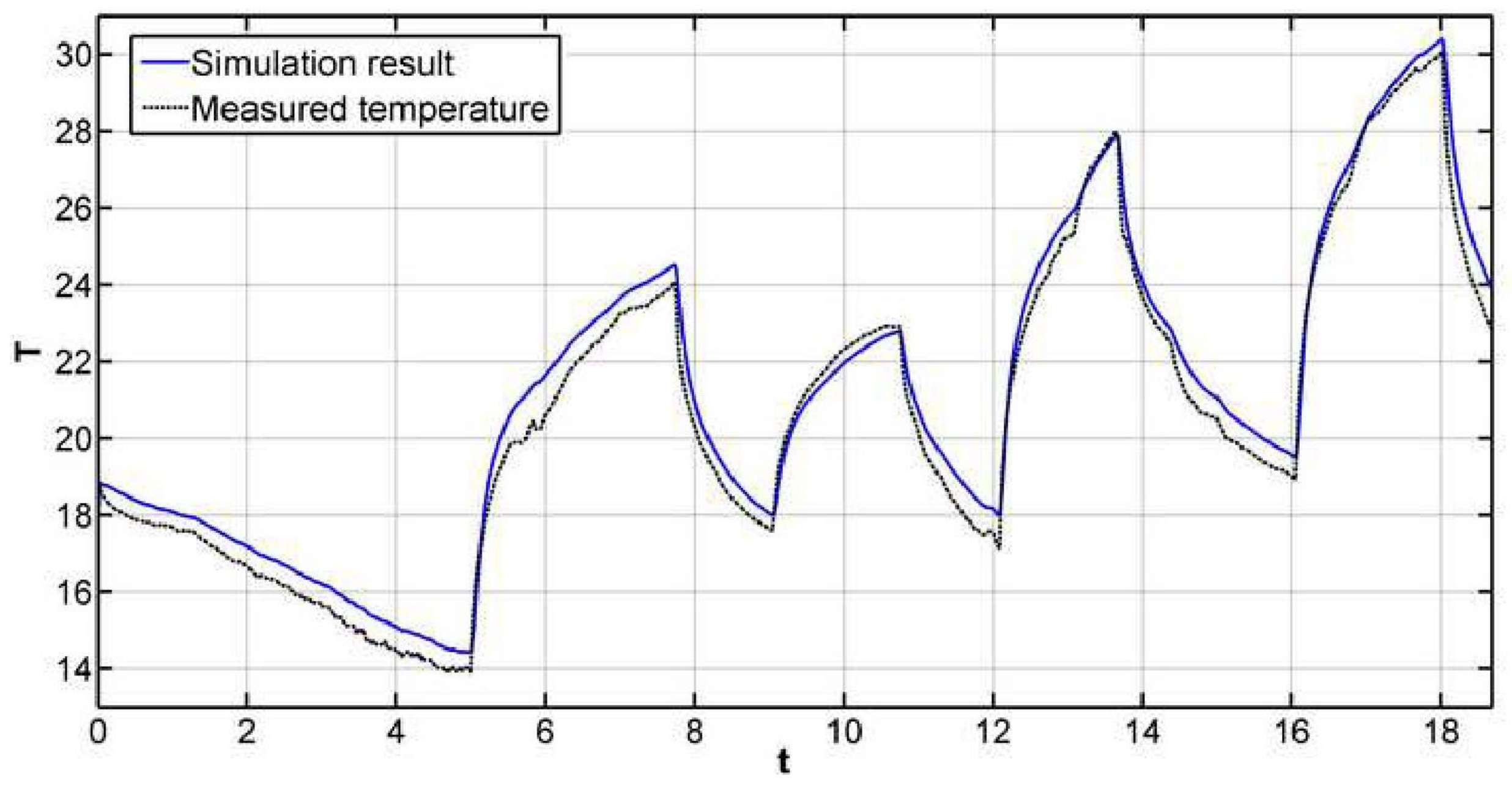




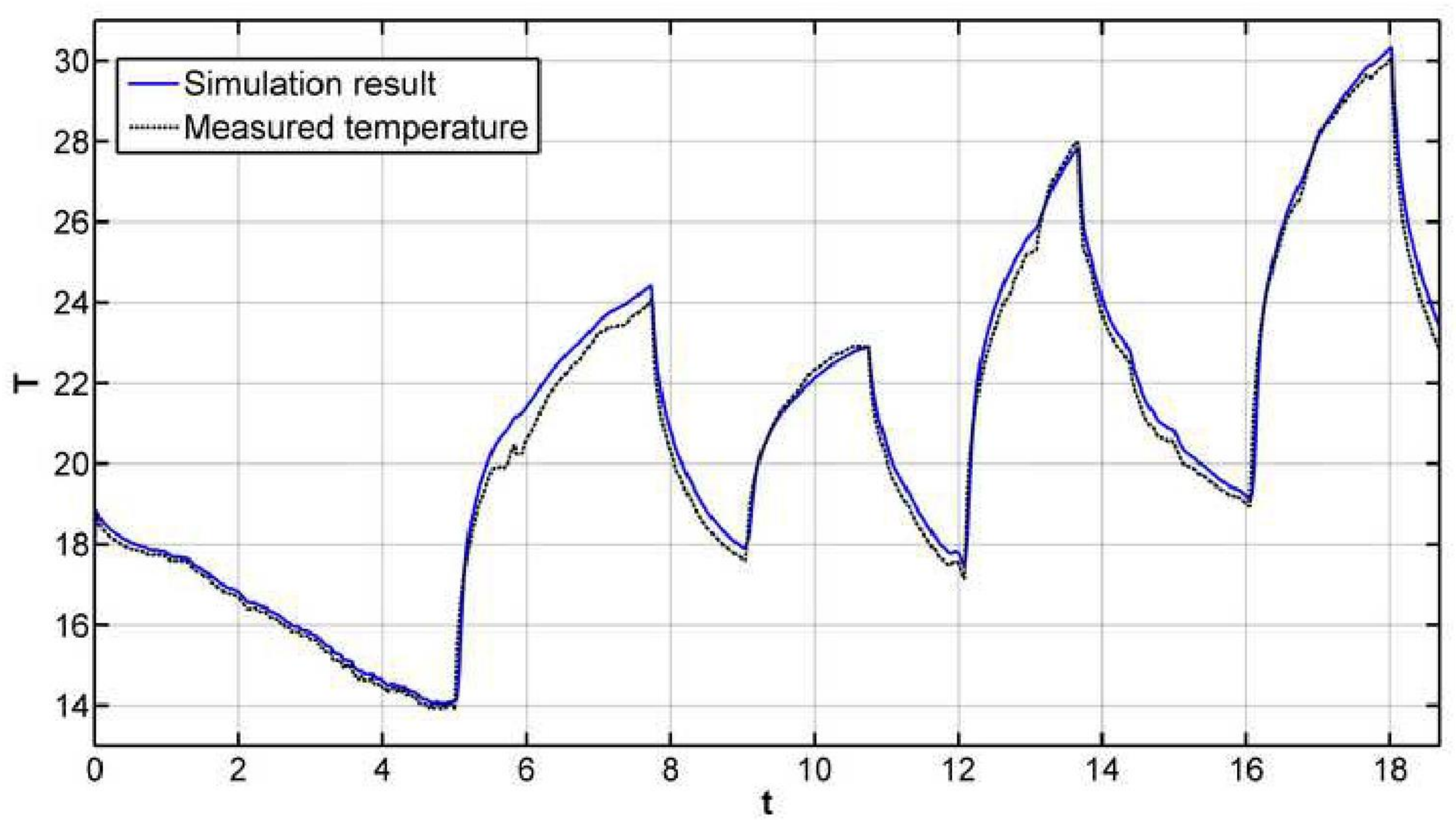




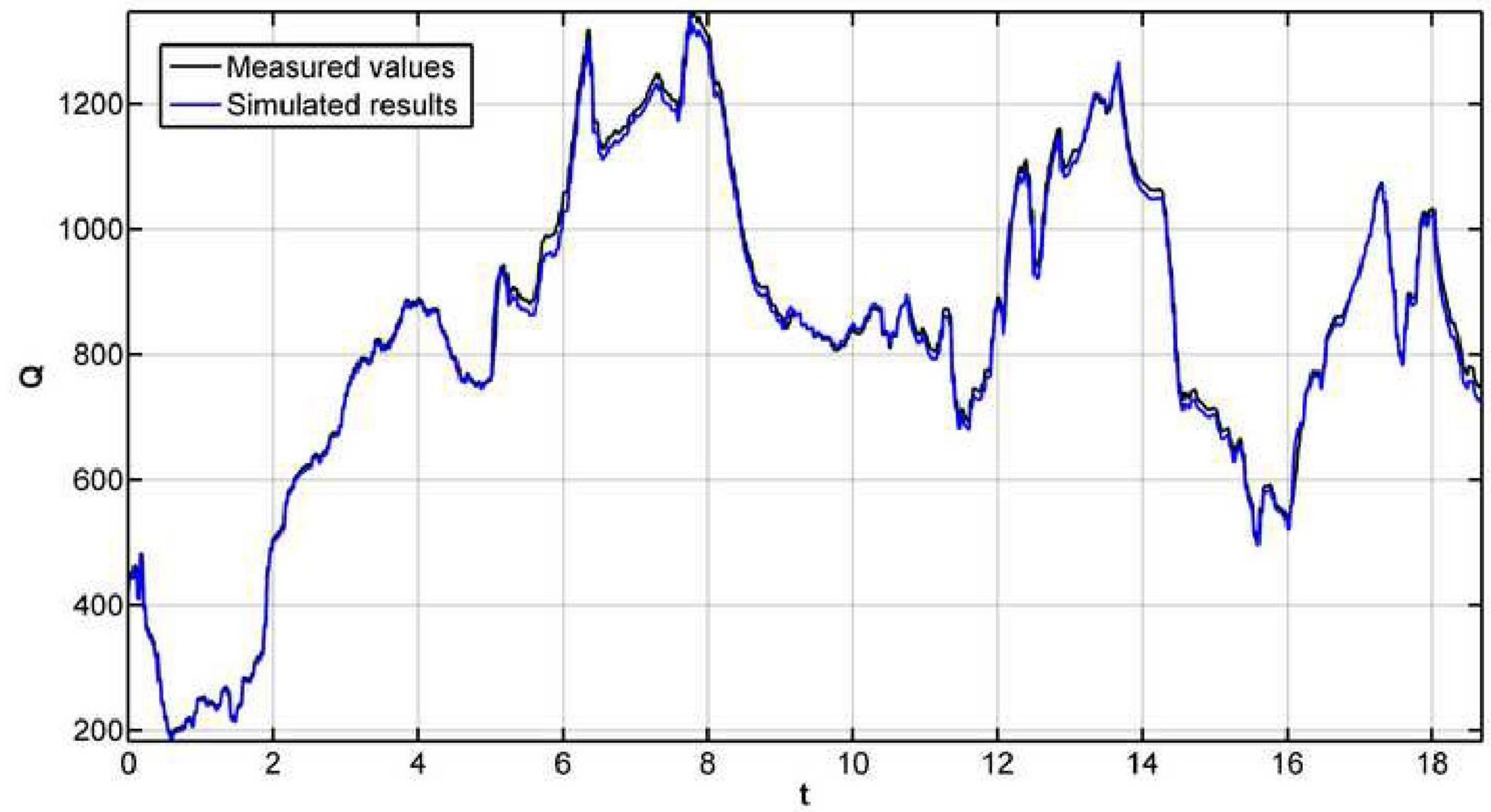




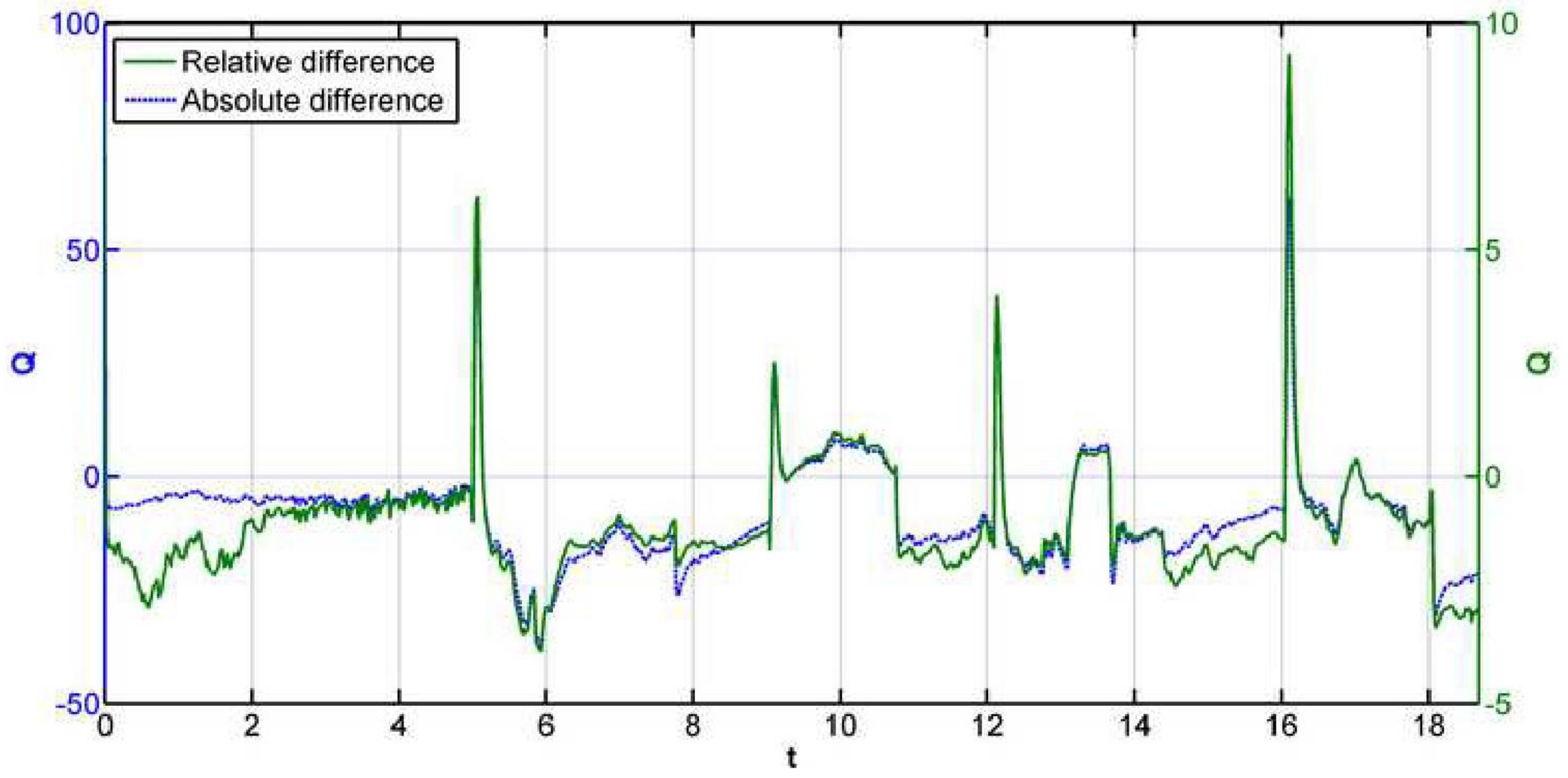




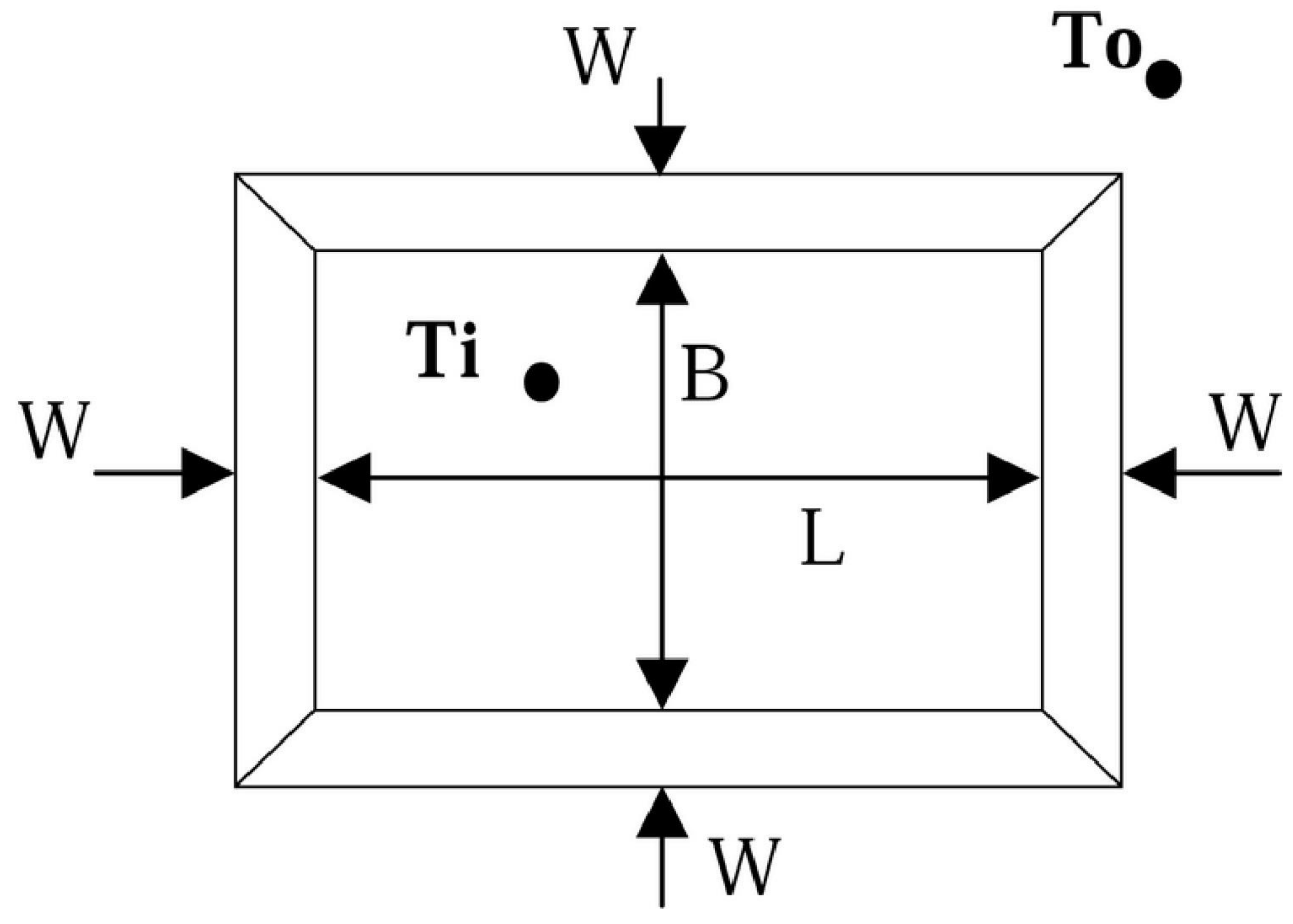




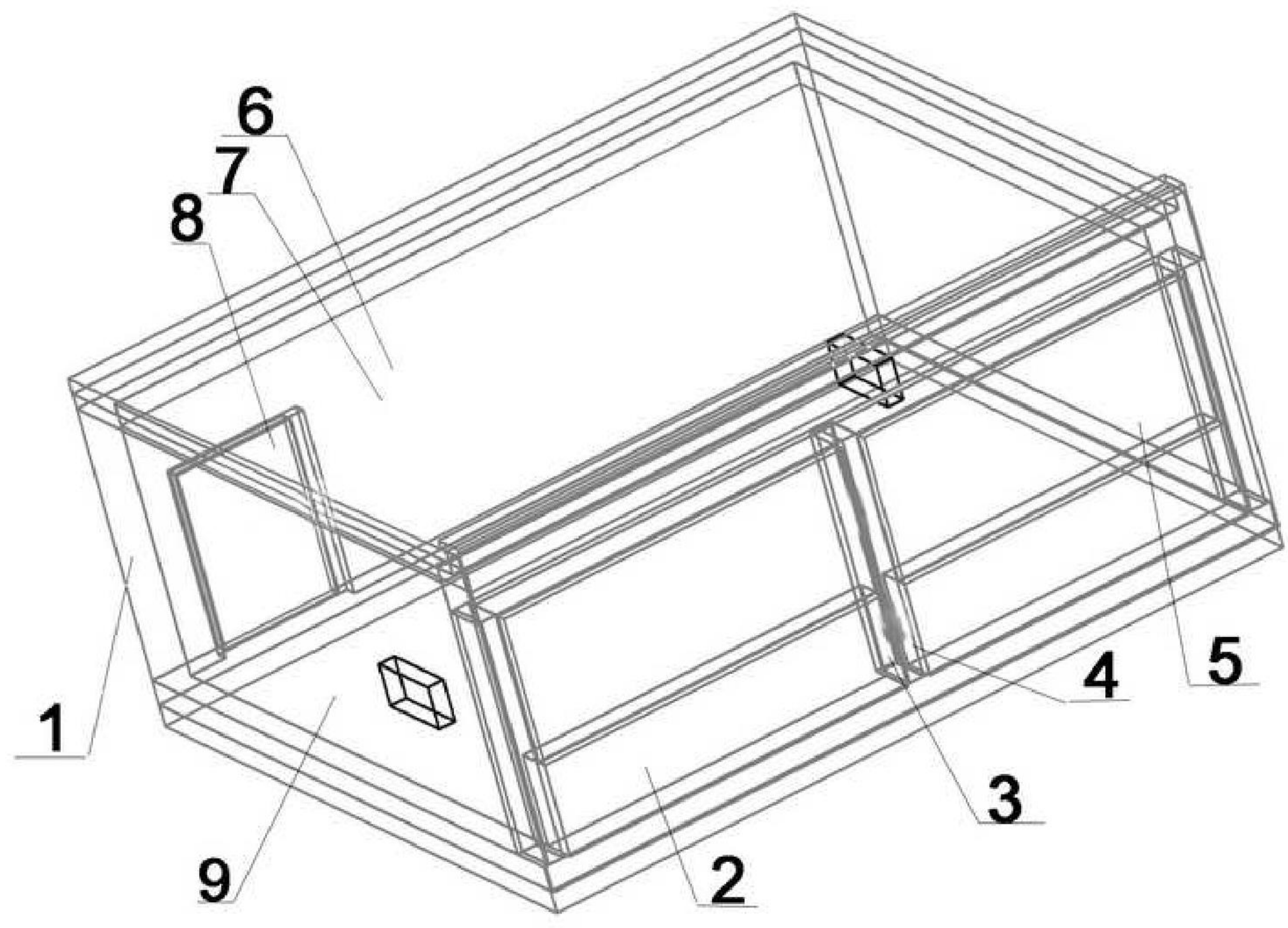




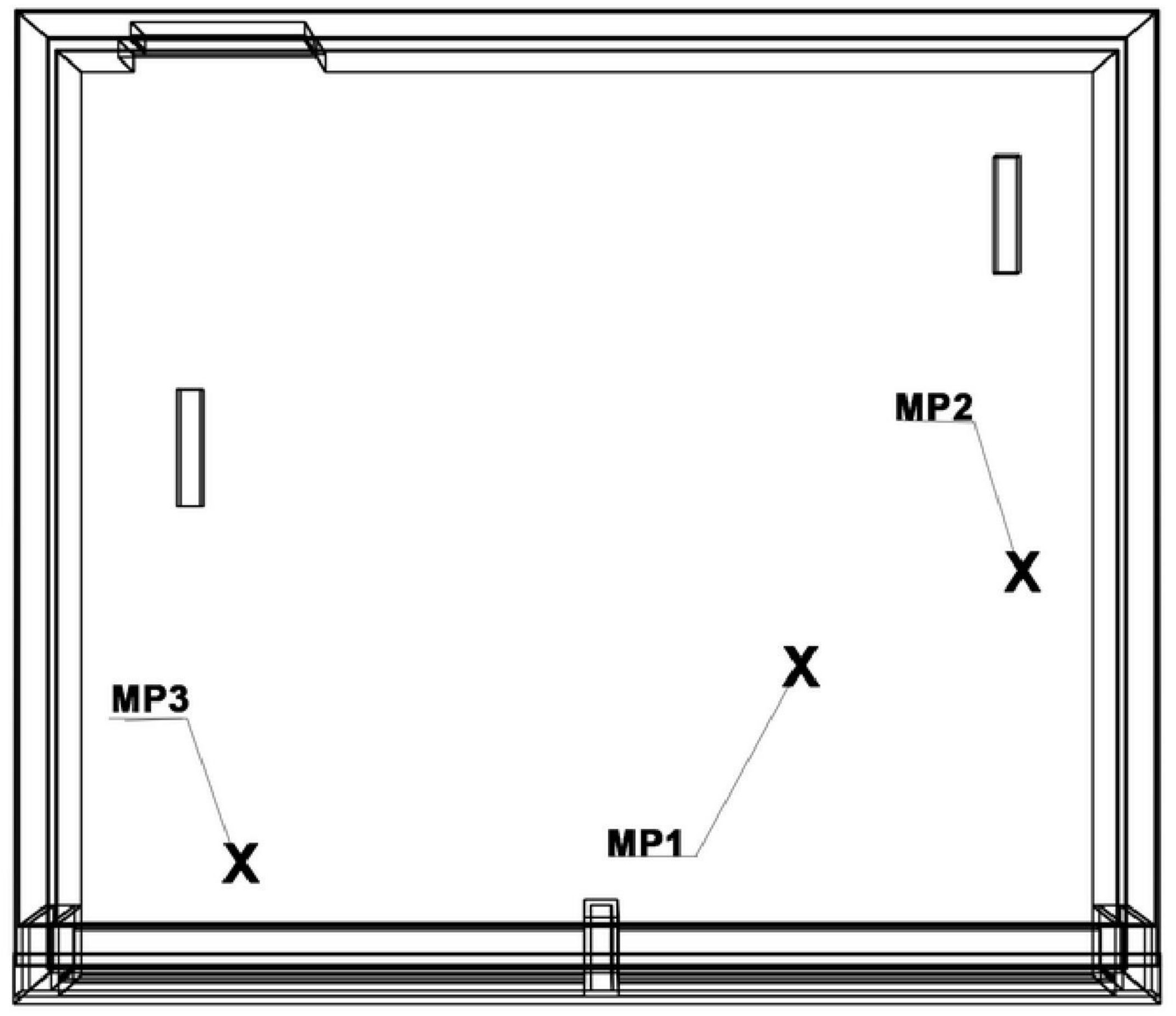




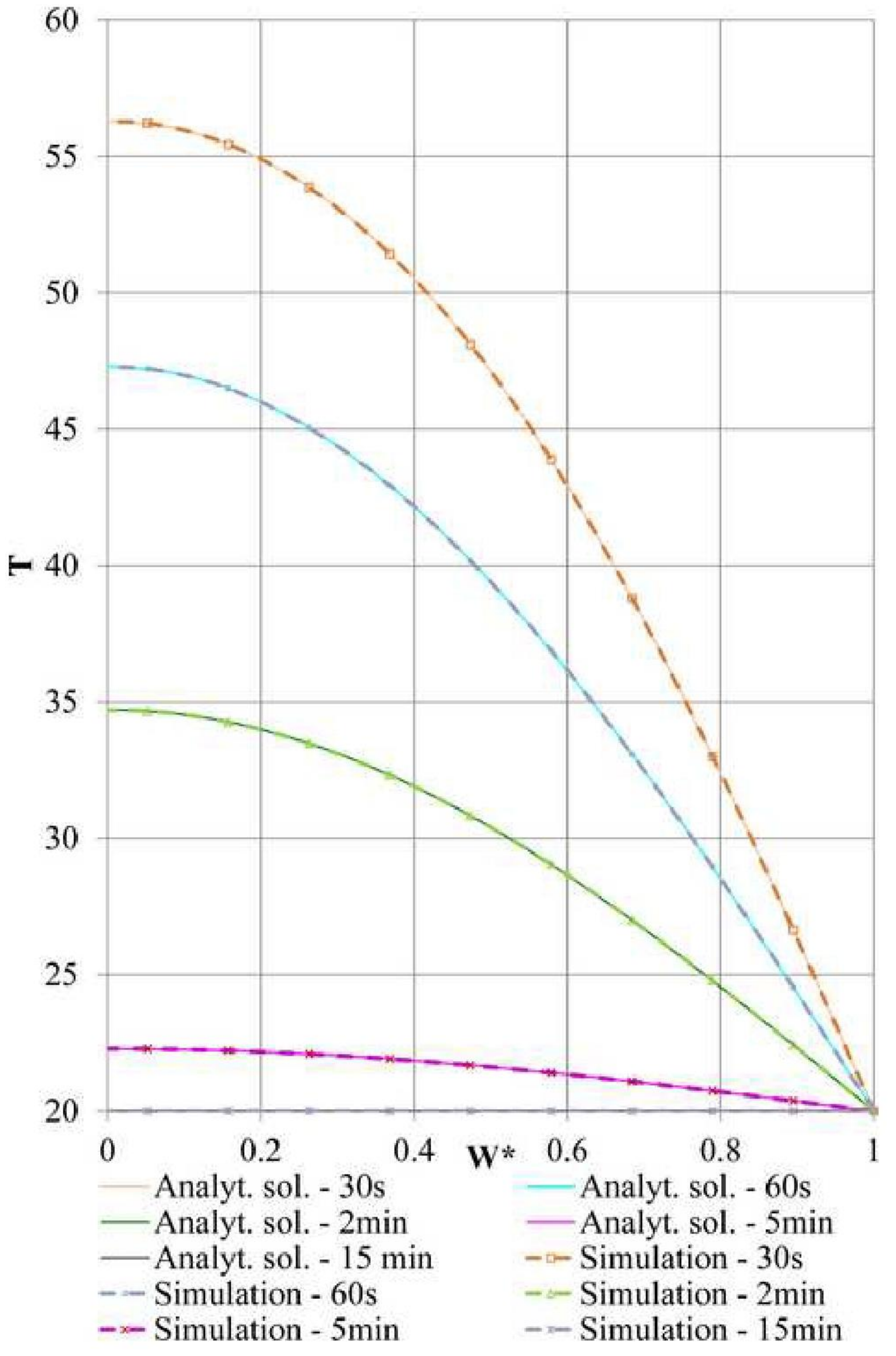




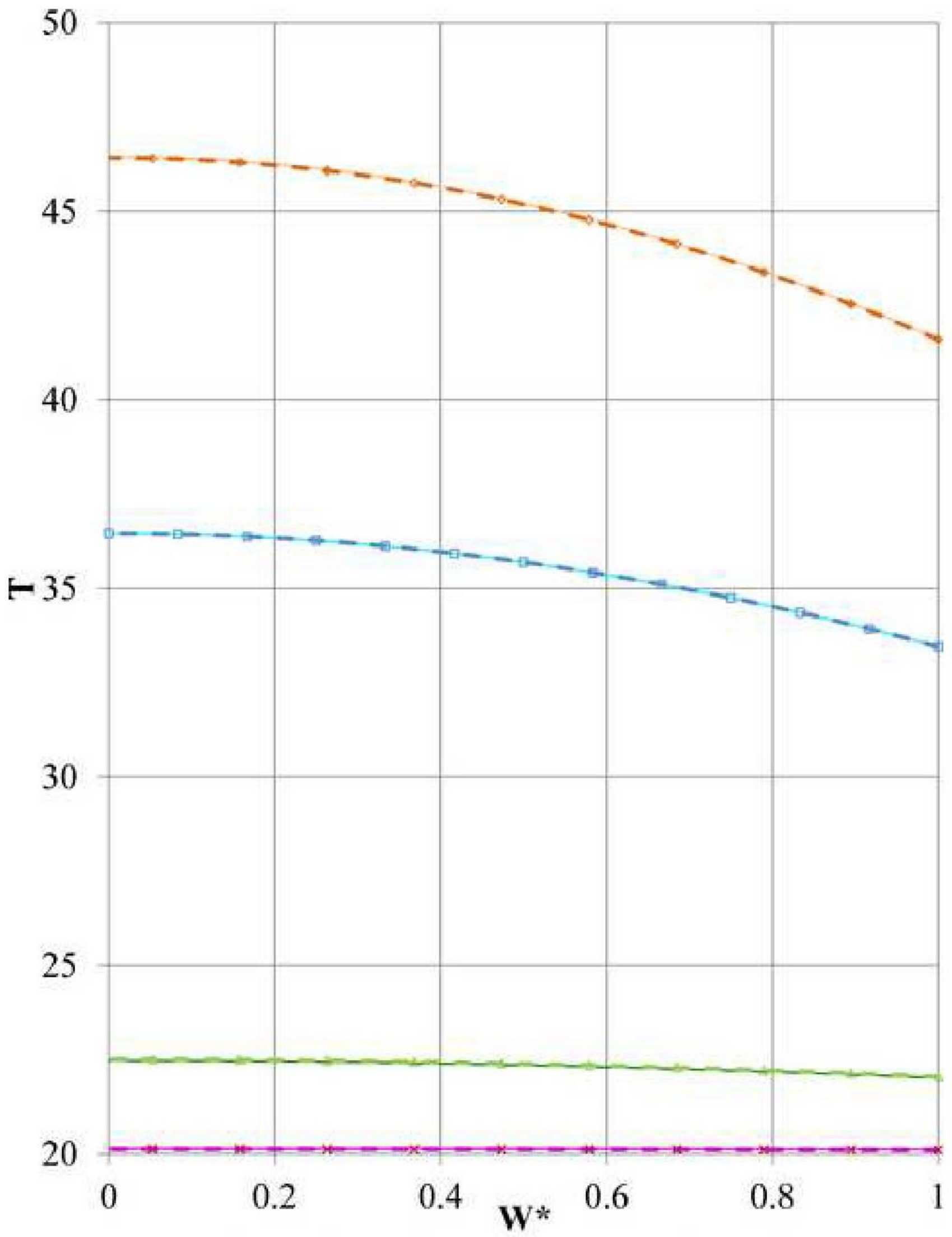

Analyt. sol. - 5min

—Analyt. sol. - 30min

Analyt. sol. - 10min Analyt. sol. - 1hour

$-\infty$ Simulation - $5 \mathrm{~min}$

$-\infty$ Simulation - 30min

$-\square$ Simulation - $10 \mathrm{~min}$

$-\infty$ Simulation - 1hour 


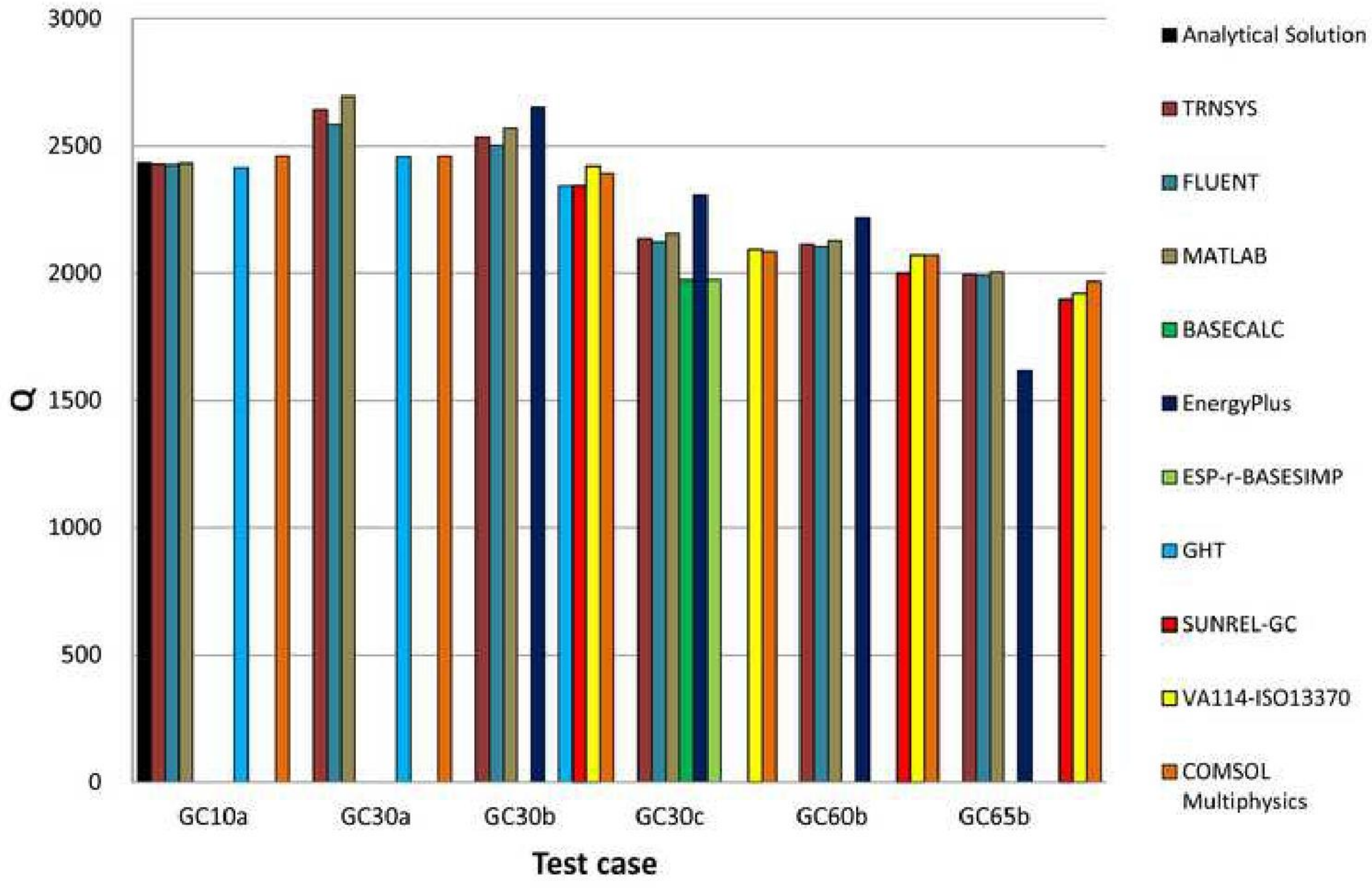




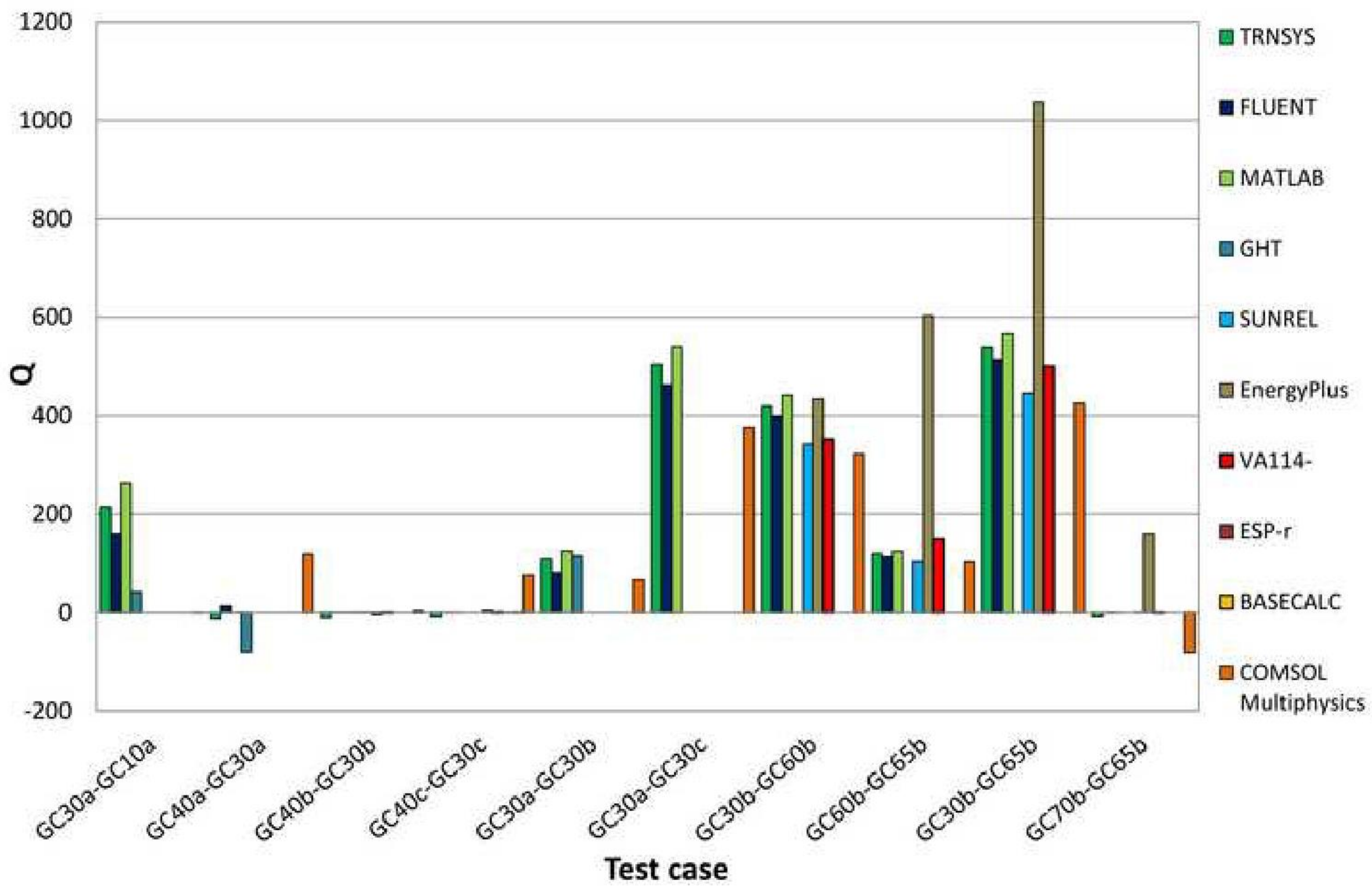




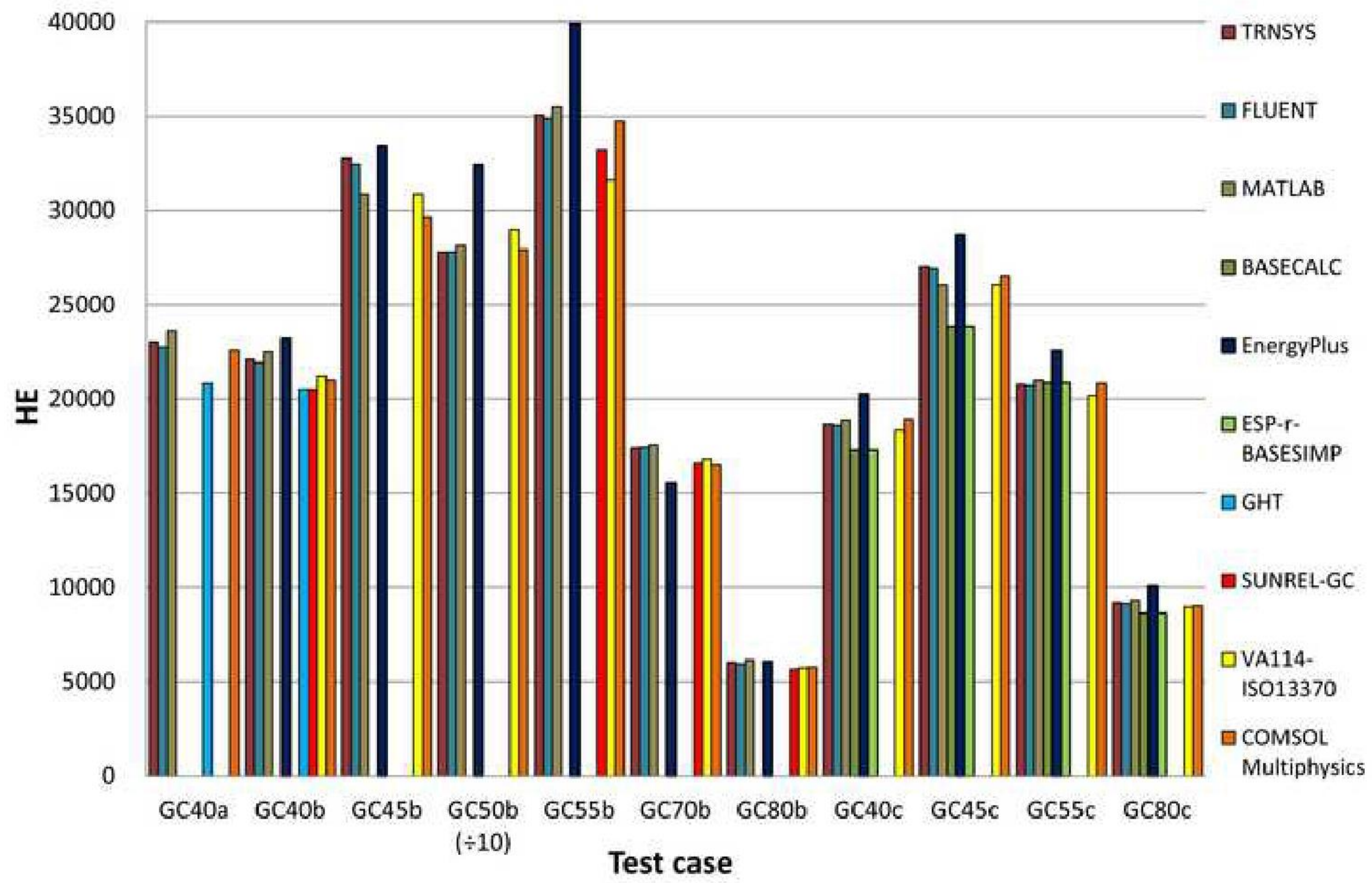


Figure 1 Schematic projection of a model discussed in Task 34 [7]

Figure 2 Plain view of conditioned zone geometry [7]

6

Figure 3 Geometry of the room model for experimental validation

Figure 4 The room plan with highlighted measuring points

9

Figure 5 Temperature distribution of analytical and numerical model with 1st-type BC 11

Figure 6 Temperature distribution of analytical and numerical model with 3rd-type BC 12

Figure 7 Comparison of CM and already validated software results - steady-state cases 12

Figure 8 Sensitivity comparison of steady-state test cases

13

Figure 9 Comparison of CM and already validated software results - transient cases

Figure 10 Sensitivity comparison of transient test cases 16

Figure 11 Comparison of temperature behaviour 20

Figure 12 Comparison of heat flux behaviour 


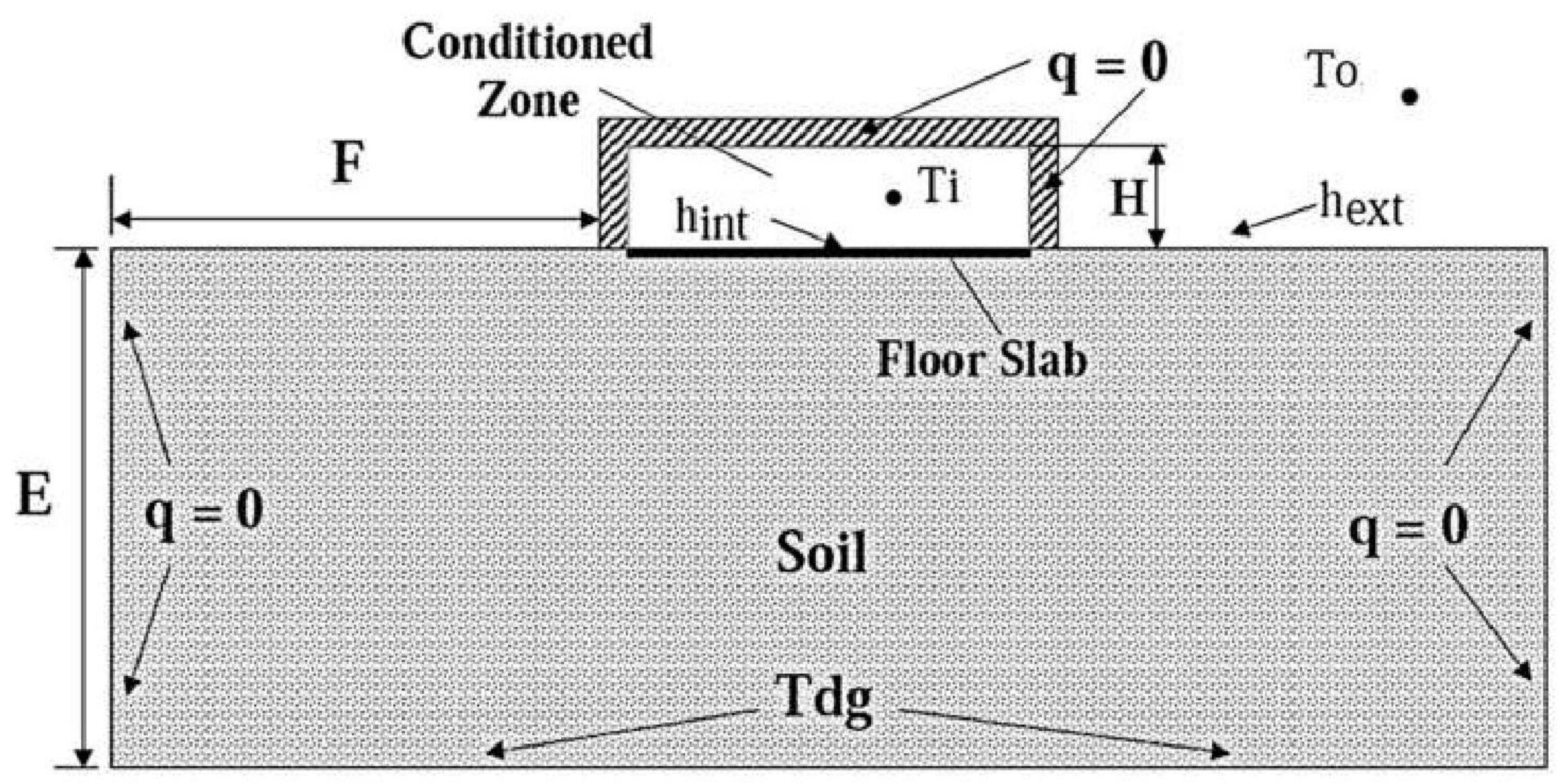


Table 1 Default geometry and physical parameters of test cases specified in Task 34

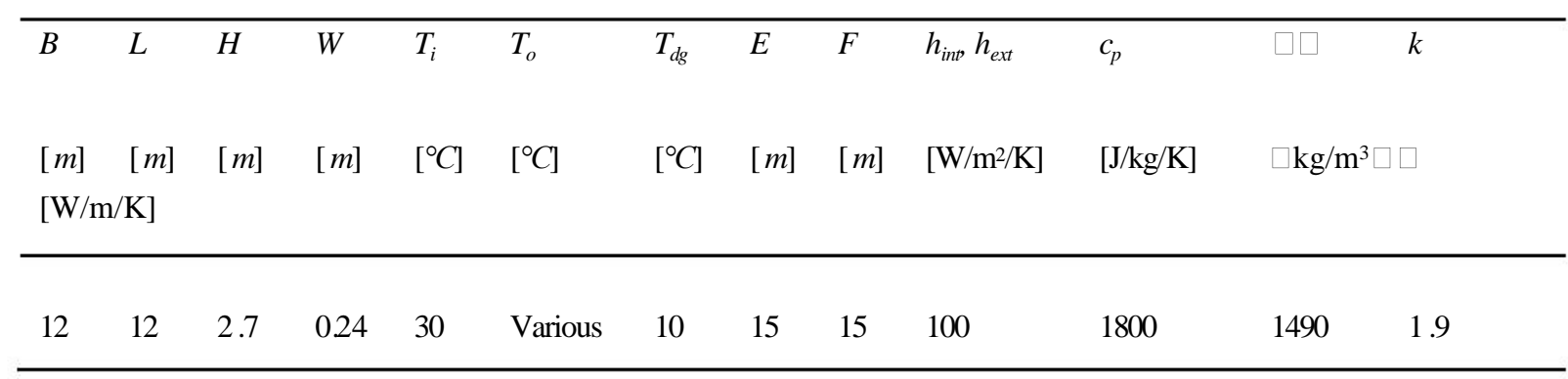

Table 2 Specific tasters

\begin{tabular}{|c|c|c|c|c|c|c|c|}
\hline Test case & Type & $\begin{array}{l}B \times L \\
{[m \times m]}\end{array}$ & $\begin{array}{l}E \\
{[m]}\end{array}$ & $\begin{array}{l}F \\
{[m]}\end{array}$ & $\begin{array}{l}h_{i n t} \\
{\left[\mathrm{~W} / \mathrm{m}^{2} / \mathrm{K}\right]}\end{array}$ & $\begin{array}{l}h_{e x t} \\
{\left[\mathrm{~W} / \mathrm{m}^{2} / \mathrm{K}\right]}\end{array}$ & $\begin{array}{l}k \\
{[\mathrm{~W} / \mathrm{m} / \mathrm{K}]}\end{array}$ \\
\hline GC10a & $\begin{array}{l}\text { Steady- } \\
\text { state }\end{array}$ & Default & 40 & 40 & Fixed T & Fixed $\mathrm{T}$ & Default \\
\hline GC30a & $\begin{array}{l}\text { Steady- } \\
\text { state }\end{array}$ & Default & 30 & 20 & Fixed T & Fixed T & Default \\
\hline GC30b & $\begin{array}{l}\text { Steady- } \\
\text { state }\end{array}$ & Default & Default & Default & Default & Default & Default \\
\hline GC30c & $\begin{array}{l}\text { Steady- } \\
\text { state }\end{array}$ & Default & Default & 8 & 7.95 & Fixed T & Default \\
\hline GC60b & Transient & Default & Default & Default & 7.95 & Default & Default \\
\hline GC65b & Transient & Default & Default & Default & 7.95 & 11.95 & Default \\
\hline GC40a & Transient & Default & 30 & 20 & Fixed T & Fixed T & Default \\
\hline GC40b & Transient & Default & Default & Default & Default & Default & Default \\
\hline GC40c & Transient & Default & Default & 8 & 7.95 & Fixed T & Default \\
\hline $\mathrm{GC} 45 \mathrm{~b}$ & Transient & $36 \times 4$ & Default & Default & Default & Default & Default \\
\hline
\end{tabular}




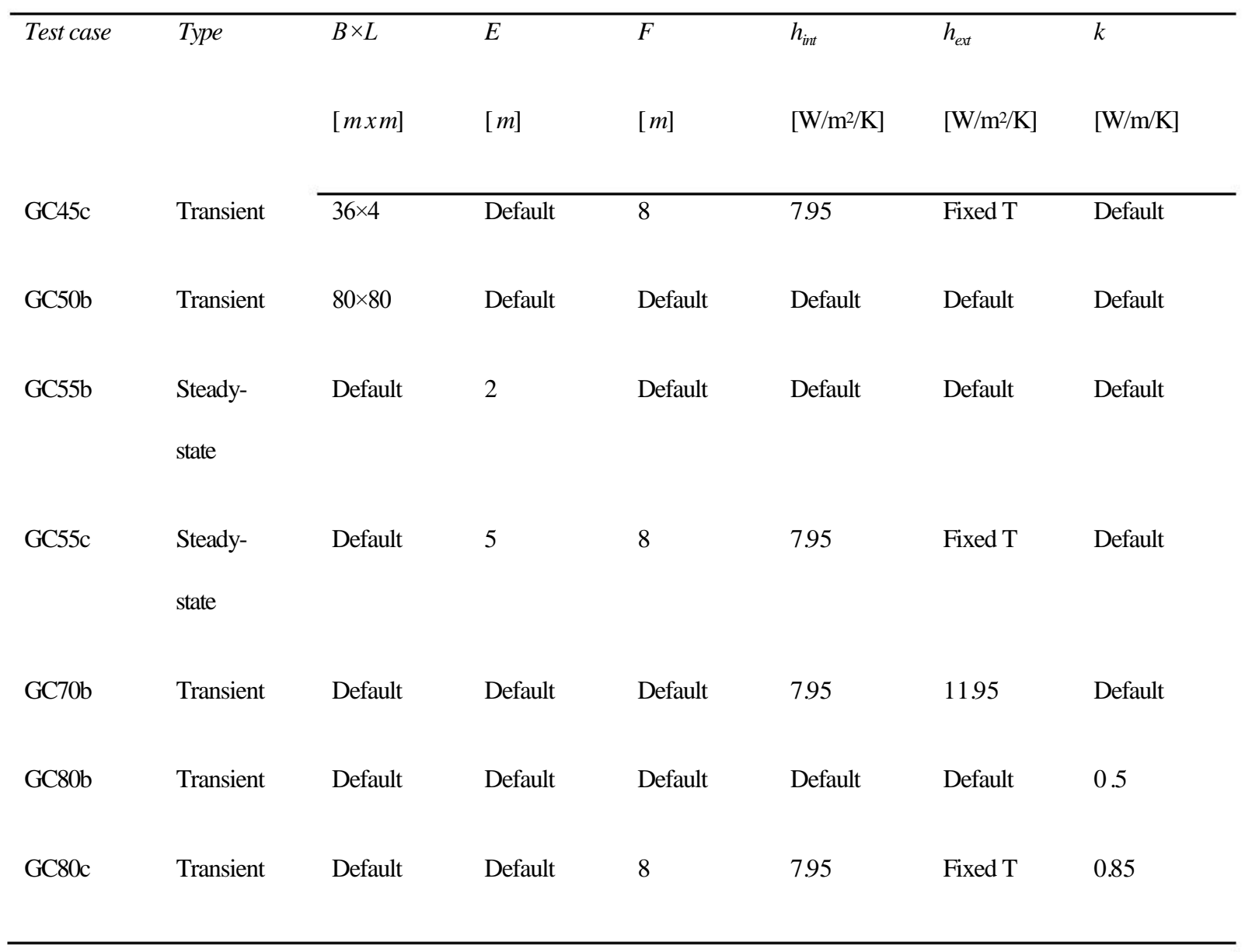

Table 3 Construction parameters used for experimental validation

\begin{tabular}{|c|c|c|c|c|}
\hline Material & $\begin{array}{c}W \\
{[m]}\end{array}$ & $\begin{array}{c}k \\
{[W / m / K]}\end{array}$ & $\begin{array}{c}R \\
{\left[m^{2} . K / W\right]}\end{array}$ & $\begin{array}{c}U \\
{\left[W / m^{2} / K\right]}\end{array}$ \\
\hline Porotherm 300 & 0300 & 0.250 & 1200 & 0.833 \\
\hline Porotherm 400 & 0.400 & 0.150 & 2.670 & 0.375 \\
\hline Polystyrene (external wall) & 0.050 & 0.034 & 1.471 & 0.648 \\
\hline Polystyrene (roof) & 0280 & 0.034 & 8235 & 0.121 \\
\hline Concrete (roof) & 0.180 & 1.430 & 0.126 & 7.940 \\
\hline Concrete (floor) & 0290 & 1.430 & 0.203 & 4.931 \\
\hline
\end{tabular}


Table 4 Stationary test case deviations calculated by CM

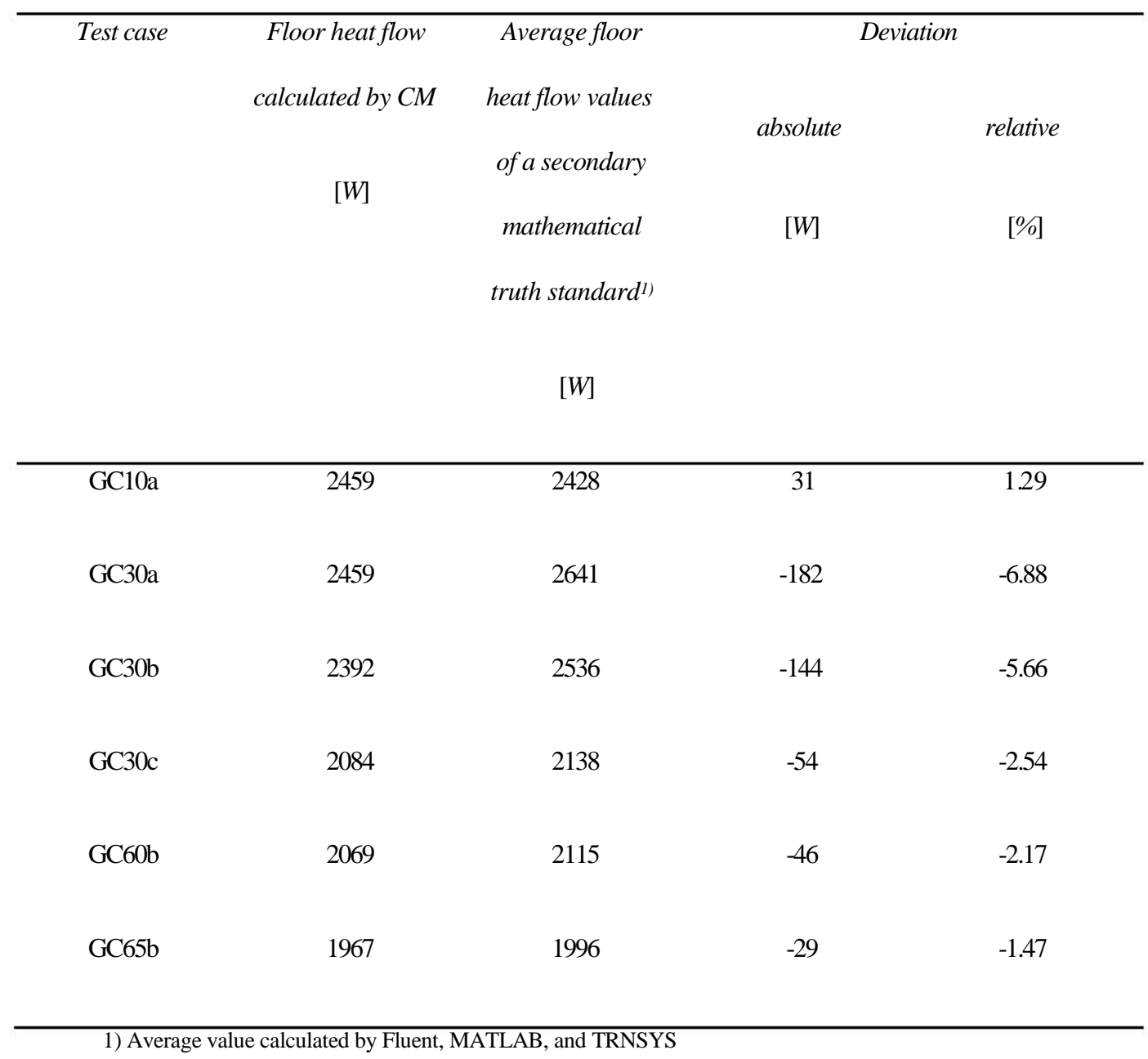

Table 5 Confrontation of six validated software with the CM - stationary cases

\begin{tabular}{|c|c|c|}
\hline Program name & Mean deviation $\left.{ }^{l}\right)$ & Standard deviation ${ }^{1)}$ \\
\hline & {$[\%]$} & {$[\%]$} \\
\hline $\mathrm{GHT}^{2)}$ & 5.06 & 3.21 \\
\hline SUNREL-GC ${ }^{3)}$ & 6.07 & 1.14 \\
\hline EnergyPlus4) & 9.12 & 5.88 \\
\hline VA114-ISO133704) & 3.17 & 1.03 \\
\hline
\end{tabular}




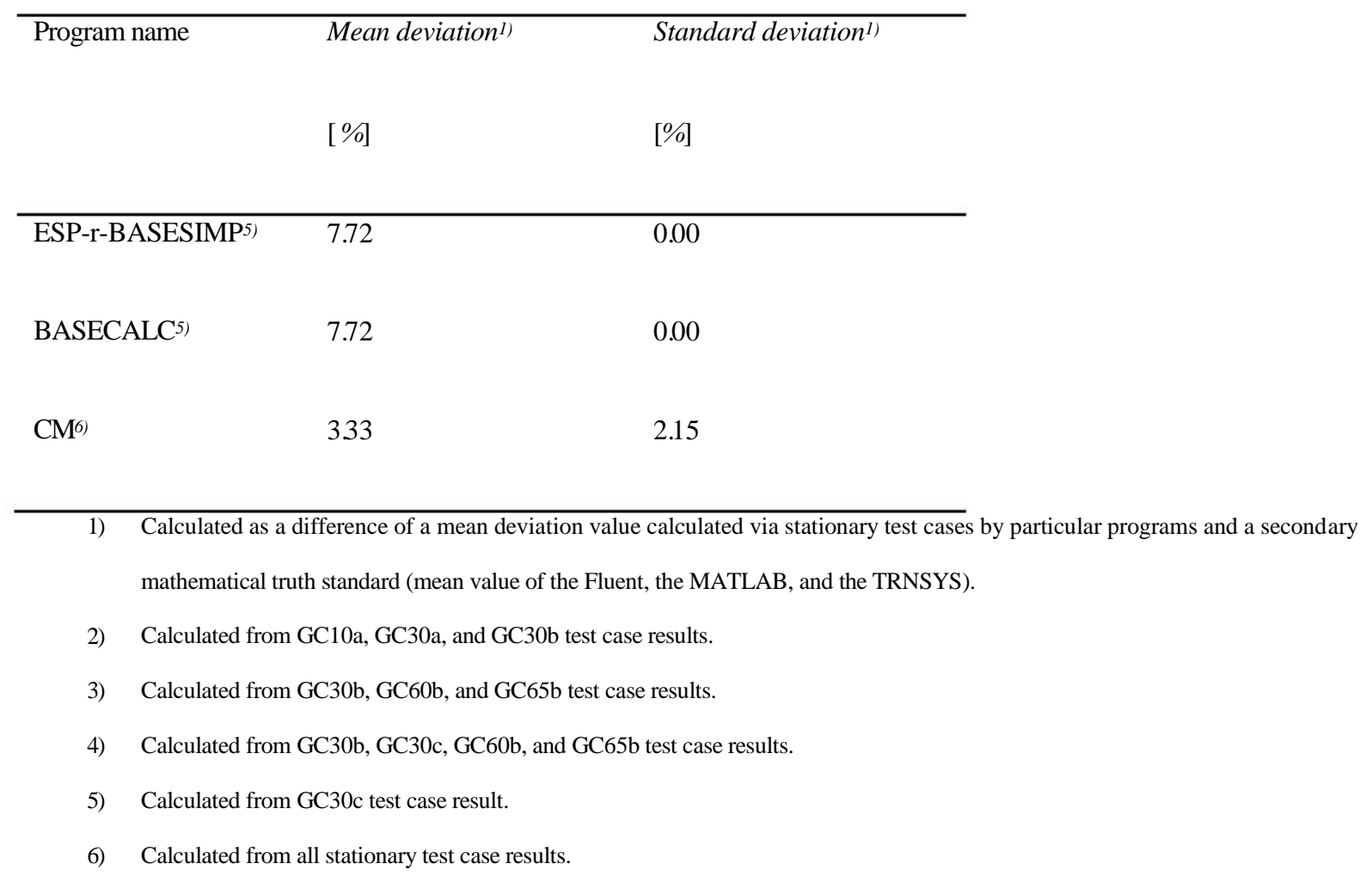

Table 6 Transient test case deviations calculated by CM

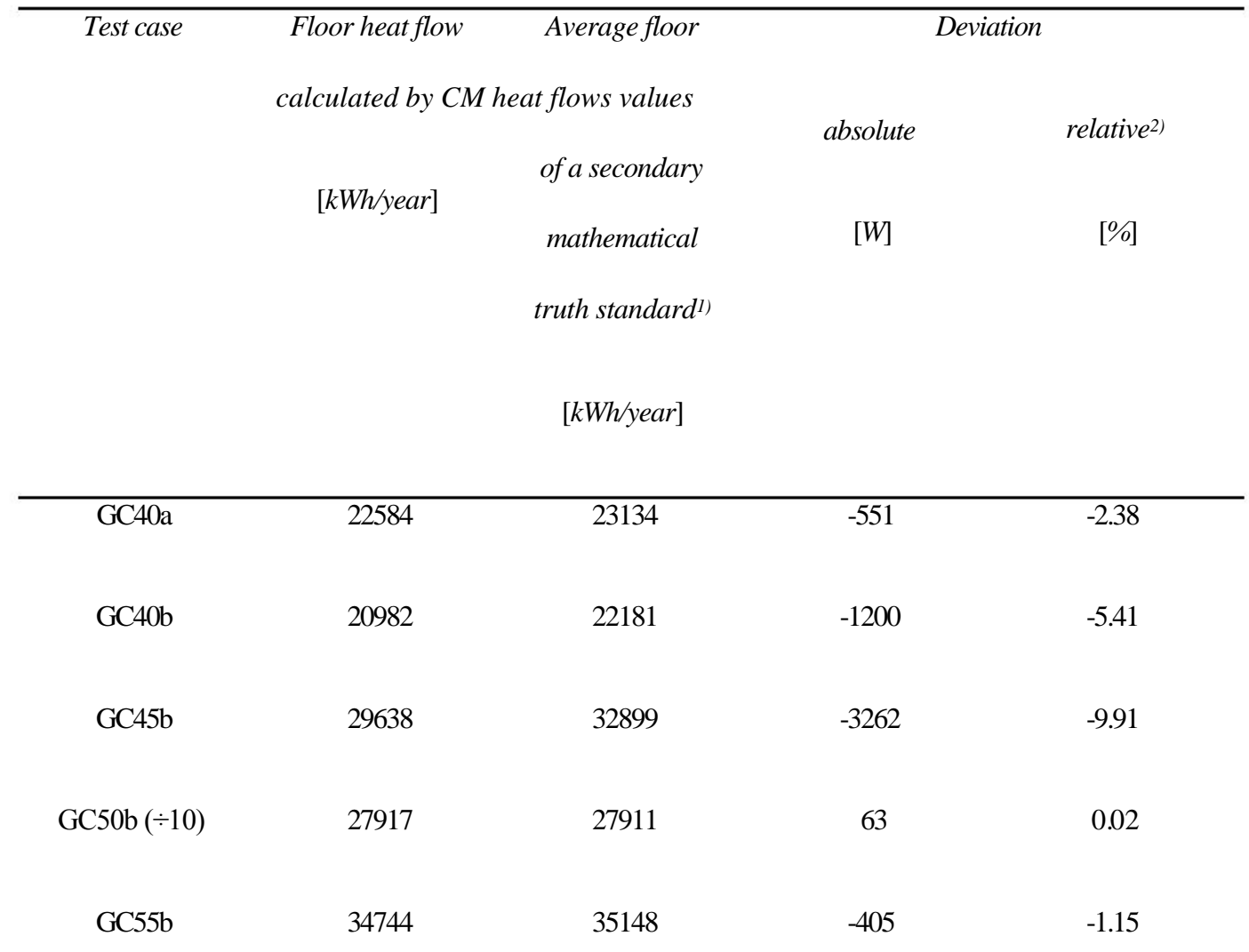




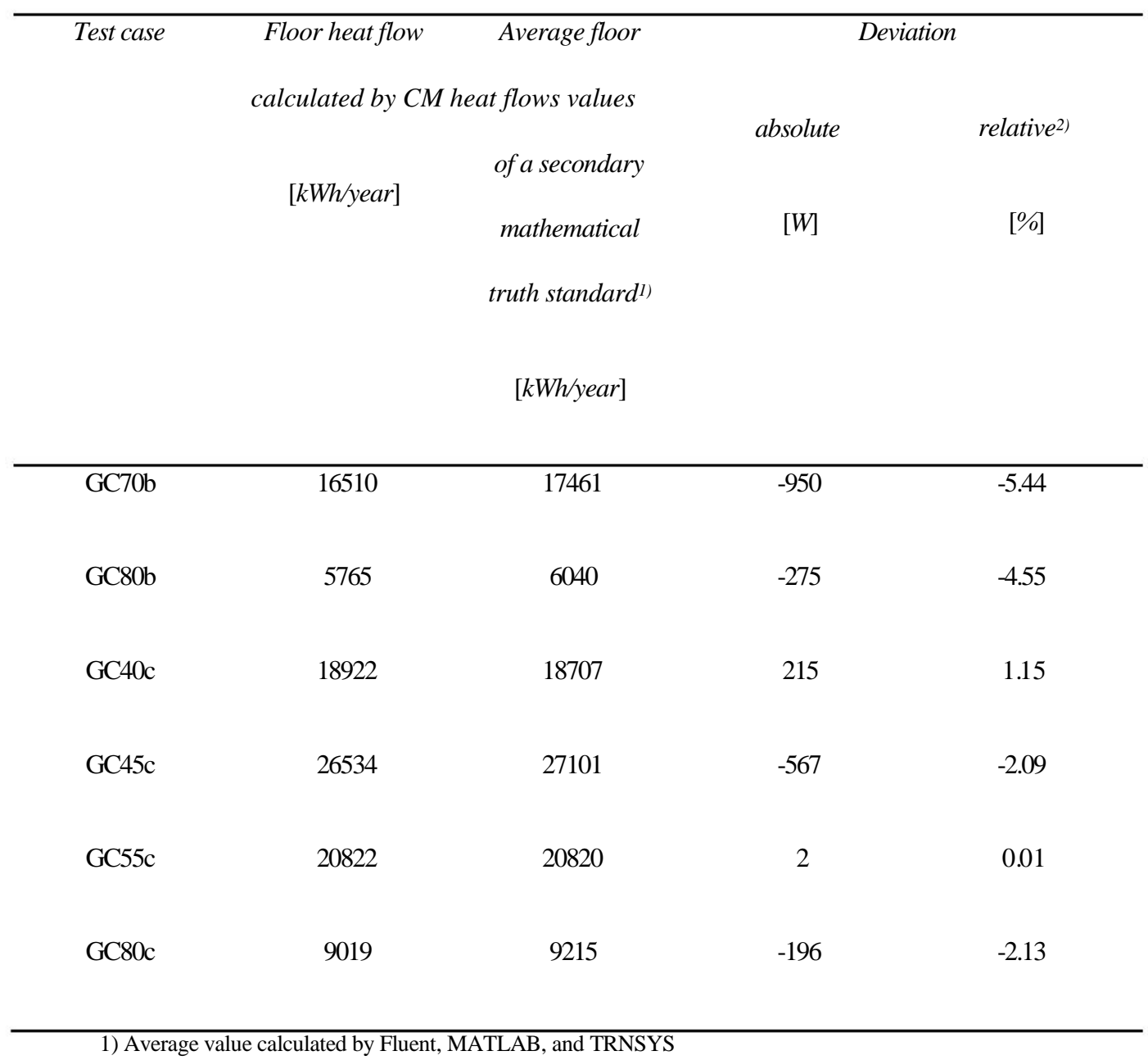

Table 7 Confrontation of six validated software with CM - transient cases

\begin{tabular}{lll}
\hline Programme name & Mean deviation $^{l)}$ & Standard deviation \\
& {$[\%]$} & {$[\%]$} \\
& & \\
\hline GHT $^{2)}$ & 8.78 & 1.26 \\
SUNREL-GC & \\
& 6.05 & 0.98 \\
EnergyPlus & & \\
& 8.37 & 4.37 \\
VA114-ISO13370 & & \\
& 4.10 & 2.19 \\
ESP-r-BASESIMP & & \\
& 6.14 & 3.78
\end{tabular}




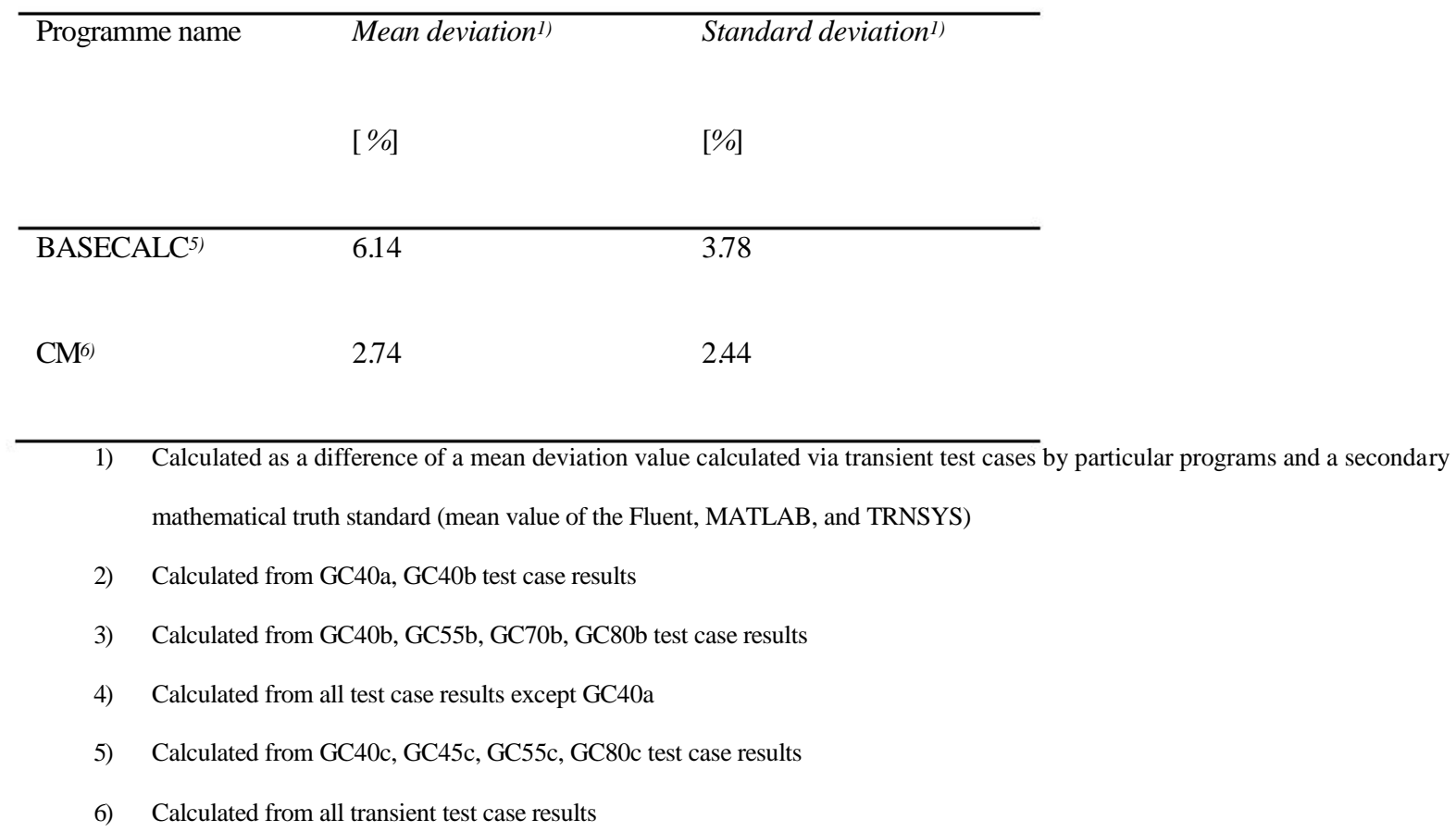

Table 8 Boundary heat losses

\begin{tabular}{lc}
\hline Boundary & $Q$ \\
& $\square$ \\
& {$[J]$} \\
\hline External wall with windows & 1336 \\
Roof & 61.94 \\
Floor and internal walls & \\
& 24.08 \\
\hline
\end{tabular}

Table 1 Default geometry and physical parameters of test cases specified in Task 34 1

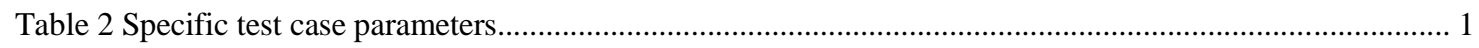

Table 3 Construction parameters used for experimental validation ......................................................... 2

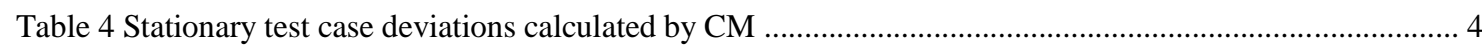

Table 5 Confrontation of six validated software with the CM - stationary cases ......................................... 4

Table 6 Transient test case deviations calculated by CM..................................................................... 5

Table 7 Confrontation of six validated software with CM - transient cases.................................................. 6 
